\title{
Evidence review and clinical guidance for the use of ziprasidone in Canada
}

\author{
David M Gardner ${ }^{1 *}$, Andrea L Murphy ${ }^{1}$, Stan Kutcher ${ }^{1}$, Serge Beaulieu ${ }^{2}$, Carlo Carandang ${ }^{1}$, Alain Labelle ${ }^{3}$, \\ Pierre Lalonde ${ }^{4}$, Ashok Malla ${ }^{2}$, Heather Milliken ${ }^{1}$, Claire O'Donovan ${ }^{1}$, Ayal Schaffer ${ }^{5}$, Jorge Soni ${ }^{5}$, Valerie H Taylor ${ }^{5}$ \\ and Richard Williams ${ }^{6}$
}

\begin{abstract}
While indicated for schizophrenia and acute mania, ziprasidone's evidence base and use in clinical practice extends beyond these regulatory approvals. We, an invited panel of experts led by a working group of 3, critically examined the evidence and our collective experience regarding the effectiveness, tolerability and safety of ziprasidone across its clinical uses. There was no opportunity for manufacturer input into the content of the review. As anticipated, ziprasidone was found to be effective for its indicated uses, although its utility in mania and mixed states lacked comparative data. Beyond these uses, the available data were either unimpressive or were lacking. An attractive characteristic is its neutral effect on weight thereby providing patients with a non-obesogenic long-term treatment option. Key challenges in practice include the need for dosing on a full stomach and managing its early onset adverse effect of restlessness. Addressing these issues are critical to its long-term success
\end{abstract}

Keywords: Ziprasidone, Expert consensus, Schizophrenia, Bipolar disorder, Depression, Anxiety, Dosing, Off-label

\section{Introduction}

Antipsychotic medications, including second generation agents (e.g. clozapine olanzapine, quetiapine, risperidone), have been prescribed more frequently, alone and in combination, and for an increasing breadth of indications in the last decade internationally [1-3]. These medications are used to treat schizophrenia and related psychotic disorders, as well as other conditions including mood, anxiety, and behaviour disorders. With the availability of a variety of antipsychotics each with a unique mix of advantages and disadvantages, clinicians and patients navigate treatment choices to identify preferred options. How do clinicians and patients make these decisions? Choosing an antipsychotic can depend on multiple complex factors. Following treatment selection, the immediate and real challenge of working towards achieving agreed upon goals of therapy begins (e.g., reduction in symptoms, relapse prevention, recovery).

The plan for this paper was to update previous work [4] and also introduce new information from a consensus

\footnotetext{
* Correspondence: david.gardner@dal.ca

'Department of Psychiatry, Dalhousie University, Halifax, NS, Canada

Full list of author information is available at the end of the article
}

panel of Canadian experts who met to develop a set of informed, clinically relevant suggestions for clinicians on the appropriate use of ziprasidone [4]. The original paper focused on schizophrenia and related psychotic disorders. This paper expands the focus to include bipolar disorder, major depression, and use in special populations. Adverse effects are extensively reviewed along with dosing and switching issues.

\section{Methods}

A panel of twelve psychiatrists and two pharmacists with relevant antipsychotic related research and clinical expertise were convened on April 16, 2010 in order to discuss and synthesize suggestions for the clinical use of ziprasidone based on current research and clinical experiences. Funding was obtained as an unrestricted grant from Pfizer Canada's community investment funding opportunity [5]. DG and SK served as the co-chairs for the meeting and AM led the development of the manuscript. At no time did the manufacturer or any of its representatives have any input into the manuscript. There were no representatives present during the meeting proceedings and they were not privy to the content of any version of the manuscript. Psychiatrists involved 
in the original publication were invited to attend by the co-chairs though not all were able to participate. New panel members, also invited by the co-chairs, with relevant clinical and research expertise were added to the panel based on pre-identified areas of interest and referrals from other panel members. Members were delegated a specific clinical area to critically analyze and present at the meeting. As well, approximately two hours were allotted and used to discuss time-intensive topics that were not sufficiently addressed by individual presentations. Prior to the start of the presentations, participants were asked to record in writing and verbally state to the group any potential conflicts of interest related to the pharmaceutical industry (e.g., grants, honoraria, advisory boards, investments, etc.) during the previous two years. During the development of this manuscript, all members were provided with two opportunities for critical and constructive feedback. This manuscript represents a synthesis of information from individual presentations, collective discussions, an extensive examination of the evidence base, and feedback from all panel members.

The following specific and general topics related to ziprasidone were sent to participants as requirements to be presented and discussed at the meeting: pharmacology, schizophrenia, early psychosis, bipolar disorder, major depression, adverse effects, cardiometabolic risk, children and adolescents, elderly, dosing by indication, and switching. Instructions were provided that presentations should cover relevant and critically appraised literature and include presenters' clinical insights on their specific topic. Participants were offered assistance with conducting literature searches for their content area by the project leaders DG and AM and a research associate. When assistance with literature searches was requested, a comprehensive search of PubMed, Embase, ClinicalTrials.gov, Web of Science, the Cochrane Library, and a related references search of individual articles as well as review of references within papers was performed. Appropriate $\mathrm{MeSH}$ and text words were chosen based on the topic and no limits were applied other than to specific age groups (e.g., elderly) when appropriate.

\section{Results}

\section{Pharmacology}

Ziprasidone exhibits high binding affinity (inhibitory constants shown as $\mathrm{pK}_{\mathrm{i}}$ with lower numbers indicating higher affinity) for select dopamine $\left(\mathrm{D}_{2}: 3.1 \mathrm{nM} ; \mathrm{D}_{3}: 7.2 \mathrm{nM}\right)$,

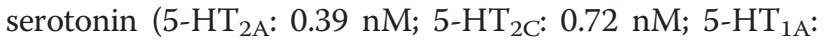
$\left.2.5 \mathrm{nM} ; 5-\mathrm{HT}_{1 \mathrm{~B} / 1 \mathrm{D}}: 2.0 \mathrm{nM} ; 5-\mathrm{HT}_{7}: 9.3 \mathrm{nM}\right)$, and adrenergic $\left(\alpha_{1}: 13.0 \mathrm{nM}\right)$ receptors and moderate affinity for the histaminic $\mathrm{H}_{1}(47 \mathrm{nM})$ and dopamine $\mathrm{D}_{4}$ (32 nM) receptors. It distinguishes itself from other antipsychotics with its agonist action at the $5-\mathrm{HT}_{1 \mathrm{~A}}$ receptor and balanced reuptake inhibition actions at serotonin (53 nM) and noradrenaline (48 nM) transporters [6-8]. Refer to Table 1 for receptor binding affinities among commonly used antipsychotics.

Several pharmacologic actions of ziprasidone have long been predicted to confer an antidepressant and anti-anxiety effect with chronic use. Serotonin and norepinephrine transporter inhibition is dose dependent with similar in vitro affinity as tricyclic antidepressants $[7,8,12]$. In vivo, the clinical significance of its monoaminergic reuptake inhibition may be limited by plasma protein binding or be clinically relevant only at higher than currently recommended daily dosages.

Activity at $5-\mathrm{HT}_{1 \mathrm{~A}}$ is similar to that of buspirone [13]. Its inverse agonist activity at $5-\mathrm{HT}_{2 \mathrm{~A}}$ receptors disinhibits dopamine neurotransmission in the nigrostriatal, tuberoinfundibular, and mesocortical pathways possibly explaining its reduced risk of parkinsonism and hyperprolactinemia $[7,14]$. This action also disinhibits dopamine release in the mesocortical pathway linking the brainstem and prefrontal cortex, an action that is putatively linked to a reduction of the negative and cognitive symptoms of schizophrenia [15].

Also predicting a low rate of movement problems, such as parkinsonism, dystonia, and dyskinesia, is its relatively high $5-\mathrm{HT}_{2 \mathrm{~A}} / \mathrm{D}_{2}$ receptor affinity ratio [16-18]. Antagonism of the $5-\mathrm{HT}_{2 \mathrm{C}}$ receptors disinhibits both dopamine and norepinephrine neurons in the cortex. This activity is predictive of improvements in cognitive and affective abnormalities as well as excitement and possibly agitation $[13,15,19,20] .5-\mathrm{HT}_{2 \mathrm{C}}$ antagonist activity has also been associated with weight gain in some models, for example the $5-\mathrm{HT}_{2 \mathrm{C}}$ knockout mouse model of obesity [21]. However, the association between $5-\mathrm{HT}_{2 \mathrm{C}}$ antagonist activity and weight gain among antipsychotics is weak [22].

Ziprasidone has a low affinity for histaminergic ${ }_{1}\left(\mathrm{H}_{1}\right)$, muscarinic $_{1}\left(\mathrm{M}_{1}\right)$, and $\alpha_{1}$-noradrenergic receptors. Among the biogenic amine receptors, $\mathrm{H}_{1}$ antagonist activity is associated with sedation and a valid predictor of weight gain liability [22]. Low affinity for $\alpha_{1}$-adrenergic receptors predicts a lower likelihood of orthostatic hypotension and sedation and low affinity for $M_{1}$ receptors predicts low rates of anticholinergic side effects including dry mouth, blurry vision, urinary retention, constipation, memory impairment, confusion, and delirium.

Using an imaging protocol, $60 \%$ or greater $\mathrm{D}_{2}$ dopamine receptor occupancy is generally predictive of antipsychotic activity. An in vivo PET study examining the affinity of ziprasidone for dopamine $\left(\mathrm{D}_{2}\right)$ and serotonin $\left(5-\mathrm{HT}_{2}\right)$ receptors observed that optimal $\mathrm{D}_{2}$ receptor occupancy occurs at the upper end ( $\geq 120 \mathrm{mg} /$ day $)$ of the recommended dosage range [23]. 
Table 1 Antipsychotic affinities $\left(K_{i}\right)$ and target daily dosing range in schizophrenia [7,9-11]

\begin{tabular}{|c|c|c|c|c|c|}
\hline Antipsychotic & Very high & High & Moderate & Low & Negligible \\
\hline daily dose & $\left(K_{i}<1.0\right)$ & $\left(K_{i} 1.0-9.9\right)$ & $\left(K_{i} 10-99\right)$ & $\left(K_{i} 100-999\right)$ & $\left(K_{i} \geq 1000\right)$ \\
\hline Ziprasidone & $5 \mathrm{HT}_{2 \mathrm{a}(0.4)}$ & $5 \mathrm{HT}_{1 \mathrm{a}(2.5) * *}$ & $a_{1(13)}$ & $D_{1}(130)$ & $M_{1(5100)}$ \\
\hline \multirow[t]{5}{*}{$120-160 \mathrm{mg}$} & $5 \mathrm{HT}_{2 \mathrm{c}(0.7)}$ & $\mathrm{D}_{2(3.1)}$ & $\mathrm{D}_{4(32)}$ & $a_{2(310)}$ & \\
\hline & & $\mathrm{D}_{3}(7.2)$ & $\mathrm{H}_{1(47)}$ & & \\
\hline & & $5 \mathrm{HT}_{7}(9.3)$ & $\mathrm{NA}_{\text {uptake (48) }}$ & & \\
\hline & & & $5 \mathrm{HT}_{\text {uptake (53) }}$ & & \\
\hline & & & $5 \mathrm{HT}_{6}(76)$ & & \\
\hline Aripiprazole & $\mathrm{D}_{2(0.3) * *}$ & $5 \mathrm{HT}_{1 \mathrm{a}(1.7) * *}$ & $\mathrm{D}_{4}(44)$ & & $M_{1(>1000)}$ \\
\hline \multirow[t]{5}{*}{$15-30 \mathrm{mg}$} & $\mathrm{D}_{3}(0.8)$ & $5 \mathrm{HT}_{2 \mathrm{a}(3.4)}$ & $5 \mathrm{HT}_{2 \mathrm{c}(15)}$ & & \\
\hline & & & $5 \mathrm{HT}_{7}$ (39) & & \\
\hline & & & $a_{1(57)}$ & & \\
\hline & & & $\mathrm{H}_{1(61)}$ & & \\
\hline & & & $5 \mathrm{HT}_{\text {uptake (98) }}$ & & \\
\hline Risperidone & $5 \mathrm{HT}_{2 \mathrm{a}(0.3)}$ & $a_{1(1.4)}$ & $5 \mathrm{HT}_{2 \mathrm{C}(10)}$ & $5 \mathrm{HT}_{1 \mathrm{~A}(210)}$ & $5 \mathrm{HT}_{\text {uptake }(1400)}$ \\
\hline \multirow[t]{5}{*}{$4-6 \mathrm{mg}$} & & $D_{2(2.2)}$ & $H_{1(19)}$ & $\mathrm{D}_{1(580)}$ & $5 \mathrm{HT}_{6}(2000)$ \\
\hline & & $5 \mathrm{HT}_{7}(3.0)$ & & & $M_{1(2800)}$ \\
\hline & & $D_{3}(9.6)$ & & & $N A_{\text {uptake }}(28,000)$ \\
\hline & & $\mathrm{D}_{4(8.5)}$ & & & \\
\hline & & $a_{2(5.1)}$ & & & \\
\hline Paliperidone & & $5 \mathrm{HT}_{2 \mathrm{a}(1.0)}$ & $a_{2(17)}$ & $5 H T_{1 A(590)}$ & $M_{1}(3570)$ \\
\hline \multirow[t]{4}{*}{ 6-9 mg } & & $5 \mathrm{HT}_{7}(1.3)$ & $\mathrm{H}_{1(32)}$ & $D_{1}(670)$ & \\
\hline & & $a_{1(4.0)}$ & $\mathrm{D}_{4}(30)$ & & \\
\hline & & $\mathrm{D}_{2(4.8)}$ & $5 \mathrm{HT}_{2 \mathrm{C}(71)}$ & & \\
\hline & & $D_{3}(6.9)$ & & & \\
\hline Olanzapine & & $\mathrm{H}_{1(2.8)}$ & $5 \mathrm{HT}_{2 \mathrm{c}(10)}$ & $a_{2(170)}$ & $5 \mathrm{HT}_{1 \mathrm{a}(2100)}$ \\
\hline \multirow[t]{6}{*}{$10-20 \mathrm{mg}$} & & $5 \mathrm{HT}_{2 \mathrm{a}(3.3)}$ & $5 \mathrm{HT}_{6(10)}$ & $5 \mathrm{HT}_{7}(250)$ & $N A_{\text {uptake (2000) }}$ \\
\hline & & $M_{1(4.7)}$ & $D_{2}(20)$ & & $5 \mathrm{HT}_{\text {uptake }}(>15,000)$ \\
\hline & & & $D_{3}(45)$ & & \\
\hline & & & $D_{1}(52)$ & & \\
\hline & & & $a_{1(54)}$ & & \\
\hline & & & $\mathrm{D}_{4(60)}$ & & \\
\hline Clozapine & & $\mathrm{H}_{1(1.8)}$ & $5 \mathrm{HT}_{6}(11)$ & $\mathrm{D}_{4(54)}$ & $5 \mathrm{HT}_{\text {uptake }}(3900)$ \\
\hline \multirow[t]{5}{*}{$200-500 \mathrm{mg}$} & & $M_{1(1.8)}$ & $5 \mathrm{HT}_{2 \mathrm{C}(17)}$ & $D_{2(130)}$ & \\
\hline & & $a_{1(4.0)}$ & $a_{2(33)}$ & $5 \mathrm{HT}_{1 \mathrm{a}(140) * *}$ & \\
\hline & & $5 \mathrm{HT}_{2 \mathrm{a}(8.9)}$ & $5 \mathrm{HT}_{7}(66)$ & $D_{3}(240)$ & \\
\hline & & & & $D_{1}(290)$ & \\
\hline & & & & $N A_{\text {uptake }}(390) *$ & \\
\hline Quetiapine & & $\mathrm{H}_{1(8.7)}$ & $a_{1(15)}$ & $M_{1(100)}$ & $a_{2(1000)}$ \\
\hline
\end{tabular}


Table 1 Antipsychotic affinities $\left(K_{i}\right)$ and target daily dosing range in schizophrenia [7,9-11] (Continued)

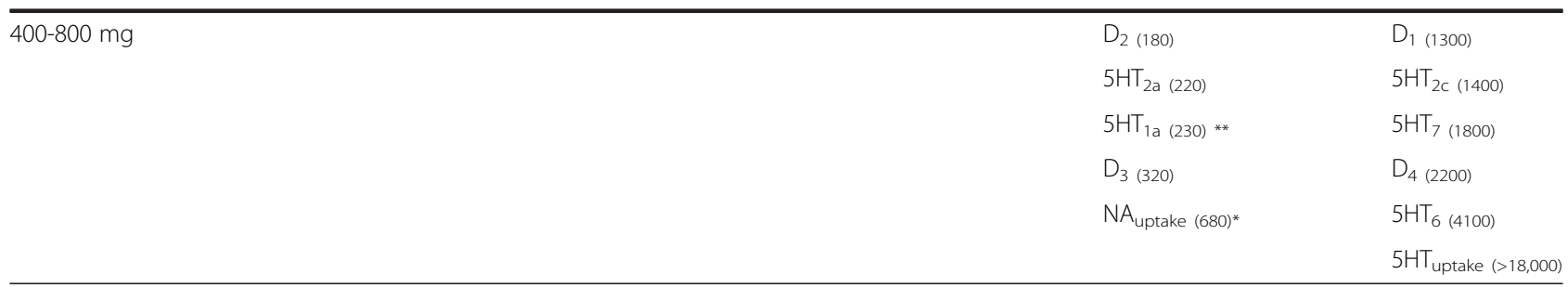

* Quetiapine's active metabolite N-desalkyl-quetiapine inhibits NA uptake (35 nM). Clozapine's active metabolite N-desmethyl-clozapine also has a low affinity for NA uptake inhibition.

** Partial agonist. Quetiapine's active metabolite N-desalkyl-quetiapine is a $5 \mathrm{HT}_{1 \mathrm{a}}$ partial agonist (191 nM). Clozapine's active metabolite $\mathrm{N}$-desmethyl-clozapine is a $5 \mathrm{HT}_{1 \text { a }}$ partial agonist $(105 \mathrm{nM})$.

5-HT: serotonin; D: dopamine; H: histamine; M: muscarinic cholinergic; a: alpha-adrenergic.

Lower values (shown in parentheses) indicate higher affinities at receptors or greater inhibition of pre-synaptic neurotransmitter uptake. Antipsychotics used in relatively small daily doses are unlikely to have clinical effects at receptors for which they have low affinity, unlike antipsychotics used at high daily doses.

\section{Pharmacokinetics}

Ziprasidone achieves peak concentration approximately 6-8 hours post ingestion and steady state concentration by the end of the second day of dosing. The typical halflife is $6-10$ hours, though individual patient values have ranged between 3 and 18 hours [14]. It is extensively metabolized, two-thirds by aldehyde oxidase, of which there are no known clinically relevant inducers or inhibitors, and one-third by P450 oxidation (3A4 > > 1A2). Potent inducers and inhibitors of CYP 3A4 may result in clinically relevant changes in ziprasidone clearance.

Unlike most antipsychotics, bioavailability of ziprasidone is approximately halved in the fasting state. To ensure optimal absorption, a meal of at least $500 \mathrm{kcal}$ is recommended with each ziprasidone dose [24]. While absorption appears to be consistent whether the meal is low or high in protein or fat content, there are no data to indicate that simple carbohydrate meals (e.g., glucosebased energy drinks) are sufficient for absorption. It is important to note that dose and concentration are linearly correlated when taken with a $\geq 500 \mathrm{kcal}$ meal but not in the fasting state. As such, doubling the dose in the fasting state does not achieve the same systemic bioavailability as taking the usual dose with food (see Figure 1). Table 2 provides calorie count examples of common foods.

\section{Schizophrenia}

The Canadian guidelines for the treatment of schizophrenia outline specific stages of therapeutic management [26]. These include individuals in the acute phase of illness requiring urgent care, first episode with little previous antipsychotic treatment, stabilization phase, stable phase, and those with multiple episodes. In addition, within these populations, subgroups such as those with persistent positive or negative symptoms, depression, suicidality, violent behaviours, inadequate response and gender differences are considered. Ziprasidone has been evaluated for many of these indications with analyses specific to some of the subgroups but details were not included in the 2005 iteration of the Canadian guidelines.

Evidence from ziprasidone randomized trials in patients with schizophrenia has been synthesized in a Cochrane Review [27]. The analysis included nine trials with the comparators amisulpride (not available in Canada), clozapine, olanzapine, quetiapine, and risperidone. In general, the quality and quantity of available data as well as extent of comparators was limited. Ziprasidone was determined to be less efficacious than olanzapine and risperidone based on PANSS total score and PANSS positive symptom subscore, especially in medium-to-long term studies [27]. Olanzapine was also associated with fewer hospitalizations

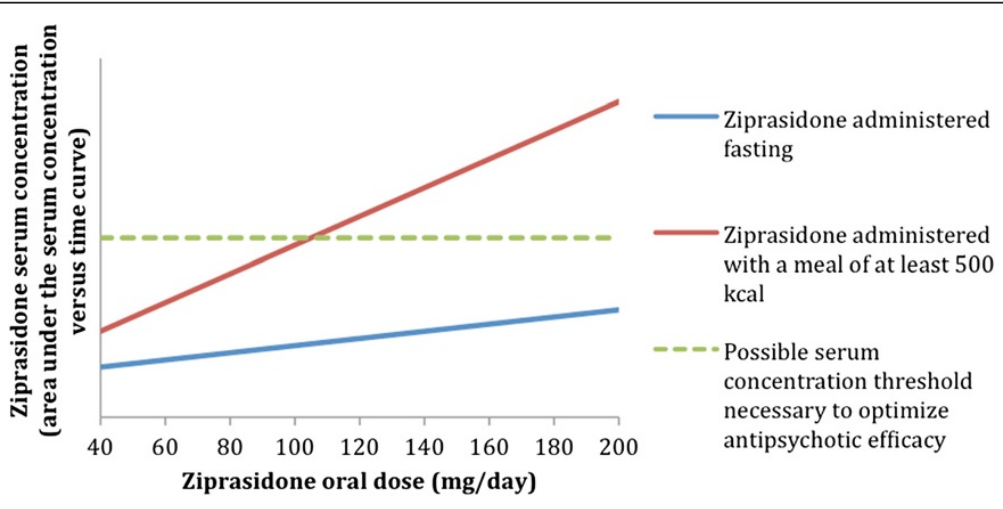

Figure 1 Affect of food on ziprasidone absorption. Reproduced with permission [25]. 
Table 2 Calories of common foods [25]

\begin{tabular}{lc}
\hline Item & Approx. kcal value \\
\hline 1 large bagel & 350 \\
1 doughnut & 120 \\
1 cup of cornflakes cereal & 100 \\
Small fast food French fries & 230 \\
Ham and cheese sandwich & 350 \\
Hamburger, with bun, plain & 270 \\
Hotdog, with bun, plain & 240 \\
Egg sandwich in English muffin & 300 \\
Danish fruit pastry & 335 \\
1 egg, boiled & 70 \\
2 snack cakes with crème filling & 250 \\
1 slice pizza & 350 \\
20 potato chips (crisps) & 200 \\
1 orange & 80 \\
1 banana & 90 \\
1 apple & 80 \\
\hline
\end{tabular}

Reproduced with permission [25].

[27]. One of the included trials comparing ziprasidone to clozapine in a head-to-head, randomized, double-blind study of 18 weeks in treatment refractory patients showed similar reductions in PANSS scores with ziprasidone and clozapine [28]. Further head-to-head trials are warranted to replicate these unexpected findings. Studies published since the review by Komossa et al., are primarily nonrandomized or non-double blind designs $[29,30]$ and several extension studies have also been published [31-33]. An extension study of 156 weeks following a 40 week randomized trial was designed to examine PANSS, quality of life scale, global assessment of functioning (GAF), and remission rates [33]. Treatment arms included ziprasidone $80-160 \mathrm{mg} / \mathrm{d}$ administered twice daily, ziprasidone 80 $120 \mathrm{mg} / \mathrm{d}$ given once daily, and haloperidol $5-20 \mathrm{mg} / \mathrm{d}$. Two hundred and twenty subjects of 599 were offered participation in the extension study and of these 186 consented to participate. In the 156 week extension study, mean PANSS negative subscale change scores per week based on last-observation-carried-forward (LOCF) were -4.86 (SD 7.64) for ziprasidone $80-160 \mathrm{mg},-3.17$ (SD 6.15) for haloperidol 5-20 $\mathrm{mg}$, and -2.87 (SD 6.48) for ziprasidone $80-120 \mathrm{mg}$. The least squares mean results of ziprasidone $80-160 \mathrm{mg} / \mathrm{d}$ compared to haloperidol were statistically different but not for haloperidol compared to ziprasidone $80-120 \mathrm{mg} / \mathrm{d}$. GAF scores for either dosage group of ziprasidone were not different from haloperidol. In the post-hoc analyses, the rate of remission as defined by a score of less than or equal to 3 for at least 6 months on eight PANSS items was $51 \%$ in ziprasidone $80-160 \mathrm{mg} / \mathrm{d}$ group and $40 \%$ in the haloperidol group. No differences existed for the lower dose of ziprasidone compared to haloperidol. In another post hoc analyses of the same trial, Stahl et al., [34] explored aspects of negative symptoms and functioning. Kaplan-Meier Survival curves indicated greater rates of remission of negative symptoms with both dosage groups of ziprasidone versus haloperidol. At 1 year these rates were approximately $60 \%$ and $50 \%$, and $35 \%$ for the higher and lower dose ziprasidone strategies and $35 \%$ with haloperidol. Another year later $\sim 15 \%$ more patients in each group attained remission from negative symptoms. The findings suggest an advantage for ziprasidone for negative symptoms and indicate the extended duration of treatment required to observe substantial improvement in negative symptoms. Findings also indicated advantage for ziprasidone on 2 of 4 subscales (role functioning and community participation) of the Quality of Life Scale (QLS).

\section{Early psychosis}

Results in first episode psychosis patients have been published across several papers based on the European First Episode Schizophrenia Trial (EUFEST) [29,35-38]. EUFEST was an open-label, randomized comparison of haloperidol, amisulpride, olanzapine, quetiapine and ziprasidone with a primary outcome of treatment discontinuation. Response rates, defined by Boter et al., [35] as symptom reduction of $\geq 50 \%$, at 12 months were haloperidol $37 \%$, amisulpride $67 \%$, olanzapine $67 \%$, quetiapine $46 \%$, and ziprasidone $56 \%$. Remissions lasting at least 6 months were observed at the following rates: haloperidol $17 \%$, amisulpride $40 \%$, olanzapine $41 \%$, quetiapine $24 \%$, and ziprasidone $28 \%$ [35].

Davidson et al., [37] reported moderate cognitive improvements with antipsychotics from the EUFEST data with no significant differences among agents [37,39]. Despite the younger patient population and use of a different first generation antipsychotic comparator, these findings are not dissimilar from the Clinical Antipsychotic Trials of Intervention Effectiveness (CATIE) results [39,40].

From available data for schizophrenia and first episode psychosis, aspects of the safety and effectiveness of second generation antipsychotics versus each other and their first generation counterparts are debatable [27,41,42]. It appears from the literature and panel discussions that ziprasidone's place in therapy is best considered for patients at risk for cardiometabolic effects, those susceptible to sedation, and as a potential first line agent in those with first episode psychosis.

\section{Bipolar disorder}

Second-generation antipsychotic studies in patients with bipolar disorder [43-46] typically show more benefits in patients with mania versus depression. Study results for second generation antipsychotics in bipolar 
depression have been mixed with quetiapine alone and olanzapine in combination with fluoxetine providing the most compelling data [47-51]. The World Federation of Societies of Biological Psychiatry (WFSBP) guidelines for bipolar depression indicate that the evidence for ziprasidone is negative [46]. The recent summary of the negative findings of two randomized, 6 week trials of ziprasidone monotherapy for people with bipolar depression sheds light on this issue. Lombardo et al. presented the results of both the fixed dose (40-80 or 120-160 mg/day), placebo-controlled study and the flexible-dose (40-160 mg/day), placebo controlled study [52-54]. Placebo response rates were $49 \%$ \& 51\% per study and ranged between $46 \%$ and $53 \%$ with ziprasidone.

Both studies were negative. Similarly, a ziprasidone augmentation study in bipolar I depression failed to find a benefit over lithium, divalproex, and lamotrigine monotherapies [55].

Ziprasidone was superior to placebo in a randomized trial of patients presenting with depressed mixed states (i.e., major depressive episode with 2 or 3 manic criteria symptoms). In an exploratory analysis ziprasidone was found to be more effective in the bipolar sample compared to the MDD sample $(p=0.036)$ [56]. Given the planned inclusion of depressive mixed state in DSM V, this study may prove to be of interest conceptually.

For patients with mania, some antipsychotics have been studied more extensively than others. For example, olanzapine has been supported as effective for not only the treatment of mania but also as maintenance therapy for the prevention of manic relapses $[57,58]$ and may also demonstrate cost-effectiveness [57]. A systematic review and meta-analysis of randomized controlled trials of second-generation antipsychotics in the treatment of acute mania (including publications to 2006) is available [59]. Yildiz et al. [60] also conducted a metaanalysis of many agents, including ziprasidone, with purported antimanic effects. The Canadian Network for Mood and Anxiety Treatments (CANMAT) lists ziprasidone as one of twelve first-line treatment options for acute mania and as an option as an adjunctive therapy in maintenance of bipolar disorder [61]. The World Federation of Societies of Biological Psychiatry guideline for treatment of acute mania [45] support the use of this agent based on their definition of " $A$ " level evidence, which primarily comes from three trials [62-64] with further information for recommendations presented based on cardiovascular safety considerations and restrictions on use. Pooled estimates [59] derived from Keck et al. (2003), [62] and Potkin et al. (2005), [63] that serve as the basis for the majority of supportive recommendations, demonstrate a standardized mean difference in YMRS scores of -0.44 (95\% CI -0.65 to $-0.23)$. This effect size estimate indicates that $67 \%$ of the ziprasidone group did better in terms of mania symptom reduction than the average placebo patient improvement [64] This was similar to individual pooled estimates for other individual second-generation antipsychotics (aripiprazole, olanzapine, quetiapine, and risperidone) as well as the combined pooled change $(-0.45$ (95\% CI -0.57 to -0.32$)$ ) for the group of antipsychotic medications [55]. Yildiz et al., [60] meta analyzed data from Keck et al. (2003), [62] Potkin et al. (2005), [63], and Vieta et al. (2010), [65] and found a number needed to treat of 5.9 (95\% CI 3.9 - 14.3) for mania management with ziprasidone compared to placebo. Few data for head-to-head comparisons are available with the exception of Vieta et al., [65] who found greater symptom reduction with haloperidol versus ziprasidone based on Mania Rating Scale (MRS) scores. Response rates at week 3 were: haloperidol 55\%, ziprasidone 37\%, and placebo $20 \%$. Vieta et al. refer to the lack of equivalence between the agents' doses (ziprasidone $116 \mathrm{mg} /$ day vs. haloperidol $16 \mathrm{mg} /$ day) [65] and others also comment in general on the relative lack of sufficiently long term trials of both placebo and head to head trials for informing decisions [60].

Pooled analyses of the trials by Keck and Potkin for subgroups of patients with a mixed manic episode and dysphoric mania are reported as positive trials [66,67]. However, in the dysphoric mania post-hoc analysis for example, baseline symptoms of depression were subsyndromal (HAM-D baseline ziprasidone $9.6 \pm 4.6$ and placebo $8.7 \pm 4.1)$. The clinical relevance of the statistical difference in mean reduction in HAM-D scores is arguably negligible (ziprasidone -4.2 , placebo -2.0 ). One study by Weisler et al. (2003), [68] is also cited in guidelines and other papers as supporting evidence but could only be found as an abstract.

Bowden et al. (2010), [69] conducted a 6 month, randomized double-blind trial of ziprasidone or placebo added to either lithium or valproate in patients with continued symptoms of bipolar I disorder (mania or mixed episode). Participants first received ziprasidone and lithium or valproate for an 8 week open label stabilization phase. Of the 584 participants that received ziprasidone add on therapy, 240 were then randomized to ziprasidone or placebo plus mood stabilizer. Approximately $67 \%$ and $80 \%$ of participants were relapse free in the placebo and ziprasidone groups at 6 months $(\mathrm{p}=0.01)$. The relapse free data was primarily attributed to differences in manic episodes for ziprasidone as depressive episodes were similar between groups. Kaplan-Meier estimates indicated a significant difference (log rank test $\mathrm{p}=0.0104$ ) for time-to-intervention for a mood disorder favouring ziprasidone. The mean difference for ziprasidone versus placebo in the mania rating scale (MRS) total score was -3.27 (95\% CI -4.91 to -1.62$)$. 
Potential advantages of ziprasidone in terms of metabolic-related side effects maintain interest in this medication for bipolar disorder. However, experiences of agitation and insomnia have limited its clinical utility in some manic and hypomanic patients. Concomitant benzodiazepine use in mania trials may have helped to limit these adverse outcomes.

\section{Depression}

The evidence for the use of ziprasidone for the treatment of major depressive disorder (MDD) is sparse. The argument for evaluating its role for the treatment of MDD is made from several perspectives including plausible pharmacological hypotheses and inadequacy of currently available treatment options.

Other second-generation antipsychotics (e.g., olanzapine, risperidone, and quetiapine) have already made the transition from use for schizophrenia to use in mania and most recently to depression. Ziprasidone's pharmacological actions, including its $5-\mathrm{HT}_{2 \mathrm{~A}}$ antagonism and reuptake inhibition of 5-HT and NE suggest an antidepressant effect. However, making explicit linkages between receptor binding profiles and clinical results in various patient groups is not straightforward. For instance, a sub-analysis of depression related outcomes in a meta-analyses of patients with schizophrenia demonstrated symptom benefits in those antipsychotics with (e.g., quetiapine) and without (e.g., olanzapine) $5-\mathrm{HT}_{1 \mathrm{~A}}$ partial agonistic effects [70].

It should be noted that, at present, there are no randomized, double-blind, controlled trials of ziprasidone in MDD published in peer reviewed journals. However, three monotherapy randomized trials have been completed (primary data collection ended June 2010 or earlier) and one ziprasidone augmentation of SSRI treatment study is expected to be completed in 2013 [71-74]. Methodological and recruitment details of each can be found at clinicaltrials.gov but no results are provided.

Other second generation agents have more information related to depression as acute therapy augmentation strategies. The CANMAT guidelines for the treatment of major depressive disorder include quetiapine as a second-line recommendation [71-74]. In those patients who have incomplete or non-response to an initial antidepressant, "first-line" approaches include addon therapy with aripiprazole (Level 1), olanzapine (Level 1), and risperidone (Level 2). Ziprasidone is suggested as add-on therapy in the third line approach with level 3 evidence [75].

A meta analysis by Nelson and Papakostas (2009) synthesized information on the use of second generation agents as augmentation therapy in major depressive disorders [76]. The odds ratio for response, as defined by $\geq 50 \%$ reduction in MADRS or HAM-D score, with second generation antipsychotics was 1.69 (95\% CI 1.46, 1.95). Odds for remission was doubled $(\mathrm{OR}=2.00,95 \%$ CI 1.69 , 2.37). Second generation agents included in the review were aripiprazole, olanzapine, quetiapine, and risperidone. Methodological issues and the unresolved therapeutic questions of what is the appropriate dose and duration of second generation antipsychotics remain despite this meta-analysis. Some agents such as quetiapine have been studied further since the time of the search conducted by Nelson and Papakostas, with promising results [77]. Komossa et al. (2010), [78] also published a systematic review of second generation antipsychotics for major depressive disorder and dysthymia and noted the relative lack of available published data for several agents including ziprasidone. Two available studies [79,80] were excluded from their analyses as they were not RCTs [78].

Two open-label randomized ziprasidone studies in treatment-resistant depression have been published. Dunner et al. (2007), [81] allocated 54 patients to combination continued sertraline therapy or add-on ziprasidone $80(\mathrm{Z} 80 \& S)$ or $160 \mathrm{mg} /$ day $(\mathrm{Z160 \& S})$. Mean change (SE) MADRS scores were -8.3 (2.2) for Z160\&S, -6.0 (1.9) for Z80\&S, and -4.4 (2.0) for sertraline alone. Possibly reflecting the small sample size, differences among groups were not significant. Differences in response ( $\geq 50 \%$ reduction in MADRS score) and remission (MADRS score < 10) rates of 6/19 (32\%), 4/21 (19\%), and $2 / 20$ (10\%), and 4/19 (21\%), $1 / 21$ (5\%), and $1 / 20(5 \%)$, respectively, were also not significant. Papakostas et al. (2004), [80] studied ziprasidone add-on therapy to SSRIs in a 6 week study with 20 patients, of which 13 completed the study. In the intention-to-treat analysis 10 of 20 participants achieved a 50\% reduction in HAM-D-17 scores and were thus defined as responders. Other small and uncontrolled investigations $[79,82]$ do not contribute significant information for therapeutic decision-making. The available pharmacological hypotheses and sparse data may warrant further exploration of ziprasidone in managing patients with MDD.

\section{Adverse events}

The prevalence and severity of various adverse effects is heterogeneous amongst antipsychotics but potential consequences can be universal and include impairment in quality of life, poor adherence, stigmatization, morbidity and mortality [83]. Similar to other antipsychotics, the risk:benefit profile of ziprasidone requires careful consideration and panel participants discussed potential merits of this agent (e.g., metabolic adverse events) alongside drawbacks (e.g., agitation). Other detailed reviews on these topics have been published [84]. During the discussions regarding adverse events, the panel focused on several clinically concerning or potentially limiting adverse events 
with ziprasidone and with reference to other antipsychotics to provide context.

\section{Agitation}

The group discussed the potential for discontinuation and other deleterious effects on patient outcomes due to therapy-related agitation. From the group's clinical experience and review of the literature, it was noted that manifestations of agitation are not well described and could be classified as illness symptoms (e.g., hypomania) or referred to as a different adverse effect (e.g., akathisia). Differences in terminology are also plausible with some references to activation [85], which may have considerable symptom overlap with manic or hypomanic symptoms, akathisia, and agitation. Patients with agitation can demonstrate a variety of behaviours (e.g., pressured or loud speech, pacing, tapping fingers or feet, starting, moaning, appearing distracted by an internal stimulus) and also manifest physiologic changes related to autonomic tone (e.g., blood pressure) and the musculoskeletal system (e.g., muscle tension) [86]. The group discussed the importance of ruling out and reversing potential contributory etiologies to the symptoms. As an example, patients with concurrent substance use problems may describe activation or appear agitated in relation to the substance dependence.

There is controversy as to whether the symptoms of agitation or activation are dose-dependent and whether any variability exists in terms of commencement of symptoms in relation to duration of therapy. Clinical experience within the group supported that agitation at lower doses is a phenomenon reported clinically by patients and suggestions were made regarding dose initiation and up-titration, as discussed later, to enhance the likelihood of adherence in early stages of treatment. Exemplifying the challenge of ziprasidone-related agitation, Kaushik (2009) [85] reported activation with higher, not lower, doses of ziprasidone, and reviews the related literature and putative mechanisms [15]. Clinicians should also be aware of reports of mania like symptoms associated with the use of ziprasidone when considering symptoms of activation and agitation [87].

\section{$Q T_{c}$ prolongation}

$\mathrm{QT}_{\mathrm{c}}$ prolongation is a risk factor for serious ventricular dysrrhythmias (e.g., Torsades de pointes (TdP)) and sudden cardiac death. The frequency of TdP with noncardiac classes of medications is not well defined but is thought to be well below $0.1 \%$ [88]. Harrigan et al. reported on the changes in QTc with 6 antipsychotics including ziprasidone [89]. The mean change in QTc (msec) was 15.9 with ziprasidone, which was approximately 9 to $14 \mathrm{msec}$ more than other included agents (haloperidol, quetiapine, risperidone and olanzapine) but less than thioridazine (30.1 msec). Addition of ketoconazole, which served as a metabolic inhibitor in the study, did not appreciably increase the QTc any further with ziprasidone $(16.6 \mathrm{msec})$ [89]. The authors also state that at no point did any participant experience a QTc greater than $500 \mathrm{msec}$, which is generally considered as approaching the threshold for TdP [89]. Miceli et al. (2010), [90] examined the effects of very high dose ziprasidone (up to $320 \mathrm{mg} /$ day) and haloperidol on QTc. The mean QTc change was $19.5 \mathrm{msec}$ (95\% CI 15.5 to 23.4) for ziprasidone $160 \mathrm{mg} /$ day and $22.5 \mathrm{msec}$ (95\% CI 15.7 to 29.4) at $320 \mathrm{mg} /$ day. One patient of 29 experienced a change in QTc of $61 \mathrm{msec}$ at the $320 \mathrm{mg} /$ day dose. No patients in either treatment arm had a QTc of greater than $450 \mathrm{msec}$ [90]. Eker et al. (2009) [91] reported on three cases of potential ziprasidone induced QTc prolongation with one patient experiencing a QTc of $510 \mathrm{msec}$ with a dose of $240 \mathrm{mg} /$ day. Resolution of QTc prolongation was achieved in all cases with dose reduction or cessation of ziprasidone. Clinical symptoms of prolonged QTc were not reported. Rocha et al. (2006), [92] reported one older nursing home patient with a QTc of $505 \mathrm{~ms}$ from a baseline of $450 \mathrm{~ms}$. The per protocol group $(\mathrm{n}=15)$ showed a $29 \mathrm{~ms}$ increase in mean QTc (baseline: $409.5 \pm 15.5$, day 49: $438.5 \pm 10.6 \mathrm{~ms})$.

In their meta analyses examining ziprasidone for schizophrenia, Komossa et al. [27] reported no apparent differences for prolonged QTc and changes in QTc from baseline with ziprasidone as compared to clozapine, amisulpride, olanzapine and risperidone. These findings are similar to those of Chung and Chua [93].

As of January 31, 2010 in Canada, Health Canada received nine voluntary, spontaneous reports of QT prolongation with ziprasidone [94]. This information is provided with the caveat that spontaneous reports have important limitations and are not appropriate for determining probability of adverse events.

Alipour et al. (2010) [95] reported a case of TdP in a ziprasidone overdose $(6 \mathrm{~g})$ with co-ingestants. They indicate that their case represents the second published overdose of ziprasidone resulting in $\mathrm{TdP}$ (the other case involved a hypokalemic 30 year old woman) and note that other overdose reports did not lead to adverse cardiac outcomes [95,96]. Tan et al. (2009) [97] conducted a systematic review in order to examine the literature for cardiovascular effects following second generation antipsychotic overdoses. In their review, 1 pediatric case of increased QTc in a child under 7 years of age receiving a ziprasidone dose of $400 \mathrm{mg}$ was identified. From case level data in adults 16 years and older, increased QTc was reported in 13 cases, ventricular arrhythmia in one, and death in two. Two cases of QTc prolongation occurred while patients were taking both ziprasidone and quetiapine in one and ziprasidone and 
risperidone in the other. The deaths were polysubstance overdoses with one patient having prolonged QTc and ventricular dysrrhythmia with suspected coingestion of amantadine, ibuprofen and ziprasidone. Hypokalemia and bradycardia were features of the patient's presentation.

Considerable discussion occurred with the panel regarding routine screening with electrocardiogram (ECG) and whether it is an effective way to detect individuals at risk for persistent prolonged QTc interval. ECG is recommended before initiating treatment with ziprasidone in patients with stable cardiac disease or if cardiac symptoms (e.g., syncope, palpitations, vertigo) occur during treatment. Clinicians should be knowledgeable of the contraindications listed in the product monograph and should also consider the many other conditions, population characteristics (e.g., older women), and medications that can affect parameters of the cardiovascular system including impulse generation, conduction, and hemodynamics. The group speculated that given the best available evidence, duration of use (since 2001 in the US and 2008 in Canada), and the potential breadth of use for off-label indications in patient types not usually reflected in clinical trials, if ziprasidone was truly associated with a risk of sudden death from cardiac causes its prevalence would be apparent from literature and clinical experience. However, concerns exist concomitantly regarding capturing postmarketing adverse reactions and the voluntary nature and low levels of reporting by health care professionals in the Canadian context. Concerns also exist for the relative low quantity of effectiveness and safety data in certain populations (e.g. pediatrics) and if off-label use was to occur in these groups, uncertainty exists as to the effects on QTc.

\section{Extrapyramidal side effects}

In the meta-analysis by Komossa et al. (2009), [27] various domains of extrapyramidal symptoms (EPS) were analyzed for ziprasidone versus other comparators (i.e. amisulpride, quetiapine, olanzapine and risperidone). There were no statistically significant differences in the rate of movement related side effects with ziprasidone versus amisulpride, quetiapine, and olanzapine. The difference in abnormal movements, akathisia severity, and parkinsonism was statistically significant in favour of ziprasidone compared to risperidone, a finding that comes from a single comparative study [98]. Based on two studies in the meta-analysis, the rates of antiparkinsonism medication use were $14.1 \%$ with ziprasidone versus $16.6 \%$ with risperidone, with a Mantel-Haenszel estimated risk ratio of 0.70 ( $95 \%$ CI $0.51,0.97$ ). The risk of using antiparkinsonism medication was significantly increased with ziprasidone (16.8\%) compared to olanzapine (10.9\%) with a Mantel-Haenszel risk ratio of 1.43 (95\% CI 1.03, 1.99). Compared to quetiapine, rates were $7.6 \%$ with ziprasidone compared to $3.3 \%$ with quetiapine with a MantelHaenszel risk ratio of 2.32 (95\% CI 1.07, 5.00). Similar findings are published by Rummel-Kluge (2010) [99].

From the available literature, arriving at conclusions with respect to EPS risk remains difficult due to differences in study design, the perspective of the analyses, the patient population, and how adverse events were captured and reported. An analysis by the CATIE investigators found no significant differences in ratings for parkinsonism, dystonia, akathisia, or tardive dyskinesia when examining second-generation agents [100]. When considering EPS in the context of switching, as per the results of three 6-week open-label studies, potential improvements with Simpson-Angus scale scores after switching from conventional agents and risperidone to ziprasidone occurred but not when switching from olanzapine [101].

Regarding serious movement disorders (e.g., oculogyric crisis, acute and tardive dystonias, tardive dyskinesia, neuroleptic malignant syndrome), the panel discussed that from clinical experience the risk of severe EPS appears to be uncommon or rare with ziprasidone but can occur. The comparative risk of individual severe movement disorders is difficult to evaluate because of their indistinct reporting in clinical trials and overall infrequency [102-108].

\section{Rash}

Pre-marketing trial data represented in product monograph information from the US for ziprasidone indicates that about $5 \%$ of patients receiving ziprasidone developed rash and/or urticaria. ${ }^{112}$ Resolution of symptoms was reported with symptomatic management (e.g. steroids, antihistamines) and/or discontinuation of treatment [109]. As reported by the manufacturer, treatment emergent adverse reactions in short term trials of patients with schizophrenia demonstrated rash in $4 \%$ of ziprasidone patients and 3\% of placebo recipients. In bipolar patients, treatment emergent pruritis was reported in $3.3 \%$ of ziprasidone patients and 2.2\% of placebo recipients [14]. Post-marketing information from spontaneous reports as cited by the manufacturer includes the potential for angioedema and Stevens Johnson Syndrome although no causality with ziprasidone has been established [14]. Published cases describe potential ziprasidone-induced angioedema, urticaria and angioedema, and photoallergic skin reaction [110-112].

As with any cutaneous reaction, the suspected etiology and contributing factors requires in depth exploration and depending on the nature and severity, consultation with specialists (e.g., dermatologists, immunologists). For ziprasidone, it is suggested that the medication be discontinued 
and re-assessed when other compelling etiologies are absent and symptomatic treatment to optimize resolution should be pursued. Expedient consultation with specialists for advice and recommendations regarding ambiguous clinical situations of cutaneous reactions may be sought when pharmacotherapeutic alternatives to ziprasidone are limited due to individual patient characteristics and/or the risks associated with discontinuation of treatment are considered to be dire.

\section{Cardiometabolic risks}

Given the concern for potential disparities in the quality of health care services for patients with mental health disorders and the higher odds of adverse health related outcomes including mortality and morbidity, consideration of therapeutic alternatives that minimize risks is essential. Differences among antipsychotics are frequently reported in studies for outcomes that are considered clinical and/or surrogate in nature (e.g., weight gain, cholesterol, glucose, etc.) and therefore these risks must be weighted with the individual patient profile and benefits.

\section{Weight gain}

The ideal measure or best discriminator (e.g., BMI, abdominal waist circumference, etc.) for predicting the risk of cardiovascular outcomes with respect to adiposity remains controversial $[113,114]$. The explicit mechanism of antipsychotic induced weight gain is not known but various theories and multifactorial explanations have been and continue to be explored including significant interest in genetics [115-122]. Foley and Morley report lower pretreatment BMI, younger age, triglyceride levels, more negative symptoms, antidepressants, and more concomitant medications were predictive of weight gain following antipsychotics initiation in first episode psychosis patients [113]. Their findings are consistent with other reviews [123]. Some researchers and clinicians have also speculated that symptom improvement for some patients may be correlated with weight gain although currently available research does not support clinically important improvements in PANSS and CGI with weight gain for patients with schizophrenia [124].

Weight gain liability varies among the commonly used antipsychotics. For example, compared to amisulpride, olanzapine, quetiapine, and risperidone, respectively, the RR of a weight gain of $\geq 7 \%$ of baseline body weight with ziprasidone was 0.48 (95\% CI 0.18, 1.29), 0.22 (95\% CI $0.14,0.33$ ), 0.45 (95\% CI 0.28, 0.74), and 0.49 (95\% CI 0.33, 0.74), respectively, identifying a distinct clinical advantage of ziprasidone therapy [27]. Mean weight change $(\mathrm{kg})$ favoured ziprasidone compared to olanzapine -3.82 (95\% CI -4.69, -2.96), quetiapine -1.20 (95\% CI -2.45 , $0.05)$, and risperidone -1.10 (95\% CI $-2.35,0.15)$ [27]. The systematic review by Rummel-Kluge (2010) similarly found a weight management advantage with ziprasidone compared to olanzapine $-3.82 \mathrm{~kg}$ (95\% CI -4.69 to -2.96$)$, quetiapine -1.2 (95\% CI -2.45 to 0.05$)$, and risperidone $-1.1 \mathrm{~kg}(95 \% \mathrm{CI}-2.35$ to 0.15$)$ [125]. In a database analyses, Parsons et al. (2009) [126] examined data of short and long term placebo and active controlled trials of various antipsychotics. The longterm trials for the antipsychotics studied (i.e., haloperidol, olanzapine, risperidone, ziprasidone, and placebo) included 1649 patients with 450 patients treated for up to 6 months and 470 patients with potential exposure for up to one year. For ziprasidone long-term trial data $(\mathrm{N}=1080)$, the random effects model for a weight gain of greater than $7 \%$ was $12 \%$ (95\% CI $8 \%, 16 \%$ ) and for weight loss greater than $7 \%$ was $16 \%$ (95\% CI 11\%, 21\%). Mean weight change per month was a mean of 0.37 pounds (95\% CI $-0.83,-0.09)$ and the median loss was 0.17 pounds [126]. In the CATIE trial (2005) [127], weight gain of $\geq 7 \%$ from baseline to last observation occurred in $30 \%$ of olanzapine, $16 \%$ of quetiapine, $14 \%$ of risperidone, $12 \%$ of perphenazine, and $7 \%$ of ziprasidone patients.

Weiden et al. (2008) [128] analyzed data from participants $(\mathrm{N}=185)$ in three ziprasidone pre-marketing (between 1997 and 1999) extension studies that were originally 6 weeks in duration and could be extended to a maximum of 58 weeks. In the first phase of the study patients were switched from risperidone $(\mathrm{N}=43)$, olanzapine $(\mathrm{N}=71)$ and conventional antipsychotics $(\mathrm{N}=71)$ to ziprasidone. In the extension phase, $61 \%$ of participants discontinued treatment by 58 weeks with $54 \%$ of those agreeing to participate in the extension study completing 32 weeks of treatment. Last observation carried forward and observed case was used for the analyses. Patients switched from olanzapine and risperidone lost $4.5 \mathrm{~kg}$ and $5.1 \mathrm{~kg}$, respectively ( $\mathrm{p}<0.01$ for both). There was no statistical difference in weight loss in those switched from conventional antipsychotics.

Switching to ziprasidone was discussed in the context of seeking improvement in weight and other metabolic parameters, however the panel noted that these potential benefits must be weighed in light of effectiveness and the chance of successful treatment with sequential agents [101,129-131].

\section{Cholesterol and glucose}

From meta-analytic data of head-to-head comparisons of second generation agents in schizophrenia [125], ziprasidone had a favourable profile as compared to olanzapine $(-15.83,95 \%$ CI -25.72 to -5.95$)$, quetiapine $(-16.01,95 \%$ CI -23.46 to -8.57$)$ and risperidone $(-8.58,95 \%$ CI -16.04 to -1.11 ) for mean difference in cholesterol $(\mathrm{mg} / \mathrm{dL})$. Ziprasidone was significantly different in terms of mean difference in glucose $(\mathrm{mg} / \mathrm{dL})$ as compared to olanzapine 
(-8.25 -95\% CI -13.72 to -2.77$)$ but not significantly different from quetiapine and risperidone. Weiden et al. (2008) [128] also demonstrated improvements in total cholesterol and triglycerides with the use of ziprasidone as compared to olanzapine and risperidone.

The link between changes in lipids and glycemic control and adverse macrovascular and microvascular complications varies among pharmacotherapies, with some drugs known to cause beneficial effects on surrogate measures but poor cardiovascular outcomes. As such, the implications of the variances in negative effects of antipsychotics on surrogate markers of cardiovascular disease should not be assumed. Weinmann et al. (2009) [132] conducted a systematic review examining the available literature on antipsychotic-related mortality, including cardiovascular morbidity and mortality, and found inconsistent findings. The authors also comment that the long term effects of second generation antipsychotics will require longer term follow-up.

Significant attention and research has also been devoted to finding interventions to attenuate or mitigate antipsychotic induced weight gain and related parameters (e.g., HbA1c, lipids) [115,126,133-138]. For example, a recent review by Maayan et al. examined 32 studies with 15 different pharmacological agents as potential treatments for antipsychotic associated weight gain [133]. The review revealed an absence of headto-head trials for pharmacological options and mixed results with regard to achieving and sustaining weight reduction benefits possibly accounted for, in part, by differences in timing of initiation of therapy. As a result, the panel discussed a need for additionally focusing efforts on prevention and health promotion. Continued study regarding morbidity and mortality trends and the etiology of these outcomes for those with symptoms of mental illnesses and disorders is required. Implementation of evidence-informed standards of care and recommendations for screening, prevention and monitoring for physical, including cardiometabolic risks, [139] and mental health care are required.

\section{Ziprasidone use in young and older populations Children and young adults}

The use of second generation antipsychotics in the pediatric population is controversial and, as accurately observed by Vitiello et al. [140], practice has expanded more rapidly than the evidence base. The primary concerns in this population are overuse, off-label use, and lack of effectiveness and safety data for specific patient groups and indications [140-160]. Concerns regarding the long-term safety of these agents require specific investigation to support informed decisions. For example, the cardiometabolic parameters (e.g., weight gain, cholesterol) potentially influenced by several second generation antipsychotics and the impact of these changes on health outcomes may not be realized for a considerable time following exposure [161].

Notably, the second generation antipsychotics are not approved by Health Canada for use in pediatrics, and in the US ziprasidone is not indicated as a first-line therapy in pediatric populations. Despite the absence of regulatory approvals of antipsychotics in pediatrics internationally (with few exceptions), these medications are used commonly in pediatrics. A recent study of US Medicaid recipients in Michigan identified 292 individuals under 21 years of age receiving ziprasidone prescriptions in the year following availability on the market in the US. The majority (58\%) of recipients were between 12 to 17 years. The data also demonstrated that in $33 \%$ of children, ziprasidone was their first antipsychotic prescription and of the beneficiaries receiving ziprasidone 53\% had a diagnosis of psychosis [162]. Thirty six percent of prescriptions were written by general practitioners. These findings suggest a general willingness to prescribe an untested psychotropic in a vulnerable patient population.

The use of ziprasidone in the child and adolescent population was reviewed recently by Elbe and Carandang (2008) [163]. An updated search did not produce additional relevant information on effectiveness. In clinical practice ziprasidone would be considered a second-line treatment for Tourette's or other tic disorders, bipolar disorder, and for autism spectrum disorders, [164,165] and it may be considered in patients in which weight gain or metabolic adverse effects to other standard antipsychotics are a particular concern $[161,166]$.

The use of this medication should be weighed in context of the available evidence for efficacy and safety in pediatrics. To date, two published prospective, doubleblind RCTs, with a combined total of 266 children, are available that examined ziprasidone for Tourette's syndrome [167] and bipolar mania, schizophrenia, or schizoaffective disorder [168]. The remaining evidence of effectiveness and safety consists of open-label, nonrandomized trials, with a total of 428 participants. From the 2008 review by Elbe and Carandang, [163] other published evidence in the form of retrospective data or case series contributes information from approximately 225 patients.

From a safety and tolerability perspective, it appears that sedation and somnolence are the most common adverse events reported with ziprasidone in pediatric populations [169]. Reports of serious adverse effects involving ziprasidone have included neuroleptic malignant syndrome $[106,170]$, EPS $[171,172]$, and changes in cardiac rate or rhythm including $\mathrm{QT}_{\mathrm{c}}$ prolongation $[173,174]$. Although published case reports are available, [175,176] accurate estimates of adverse effect 
rates are lacking. Difficulty remains with establishing recommendations for monitoring for some side effects such as QTc given the finite amount of data available from studies and post-marketing surveillance. Until more safety data is available we recommend an ECG at baseline and at the target dose when used in children and youth.

\section{Older adults}

Despite the warnings of increased risk of death [109] with the use of second-generation antipsychotics in older adults with dementia, there continues to be substantial off-label use in this population. There are no randomized controlled trials evaluating the efficacy or safety of ziprasidone in elderly patients [177]. A Cochrane Review examining atypical antipsychotics for aggression and psychosis in patients with dementia does not include ziprasidone [178]. One open-label, flexible dosing prospective case series of 25 nursing home patients with dementia, of which 15 completed the study according to protocol, by Rocha et al. (2006) [92] showed a significant reduction in the mean total neuropsychiatric inventory (NPI) score from baseline $47.1 \pm$ 17.1 (mean \pm SD) to $25.8 \pm 17.9$ at 49 days. From clinical experiences, appropriate management of agitation, aggression, and confusion, remains complex with few safe and effective therapeutic alternatives.

\section{Long-term treatment acceptability}

Persistence with prescribed treatment is a critical goal of therapy with antipsychotics ${ }^{182,183}$ and yet it remains overestimated in the clinical setting despite ample characterization of non-adherence in the literature [179-183]. Kamossa et al. (2009), [27] reviewed ziprasidone versus other atypical agents for schizophrenia and found premature discontinuation for any reason in 59\% of people randomized to antipsychotic treatment, a finding matched by others [184]. In the review by Komossa, the relative risk of leaving studies for any reason was more likely with ziprasidone as compared to olanzapine, 1.26 (95\% CI 1.18, 1.35), and risperidone, 1.11 (95\% CI 1.02, 1.20) [27]. The CATIE investigators demonstrated all cause discontinuation rates of $64 \%$, $74 \%, 75 \%, 79 \%$, and $82 \%$ for olanzapine, risperidone, perphenazine, ziprasidone, and quetiapine, respectively [127]. A recent naturalistic study in patients with symptoms of acute psychosis demonstrated discontinuation rates of approximately $60 \%$ for the second generation antipsychotics (quetiapine, olanzapine, risperidone and ziprasidone) within 100 days [181]. Kahn et al., examined the effectiveness of antipsychotic drugs in firstepisode schizophrenia and schizophreniform disorder and had 12 month discontinuation rates (any cause) of $72 \%$ (haloperidol), 53\% (quetiapine), 45\% (ziprasidone), 40\% (amisulpride), and 33\% (olanzapine) [29]. A study by Olfson et al. (2011) [160] showed discontinuation rates in the first 180 days with early onset schizophrenia to be above $70 \%$ for all agents including aripiprazole, olanzapine, quetiapine, risperidone, and ziprasidone. Many other trials with ziprasidone in patients with schizophrenia or related disorders that were small or large in scale and duration have shown similarly significant discontinuation rates regardless of their design (i.e., prospective or retrospective) $[30,31,33,185,186]$.

Rates of discontinuation are similarly high for other mental disorders. Randomized studies in patients with bipolar disorder demonstrate completion rates of 54\% and $61 \%$ for ziprasidone versus $85 \%$ and $44 \%$ for placebo $[58,59]$. Vieta et al. showed completion rates of $45 \%$ for haloperidol, $41 \%$ for ziprasidone and $28 \%$ for placebo in patients with acute mania in a 12 week study [60]. In patients with treatment resistant depression who were randomized to either open-label sertraline monotherapy or sertraline and ziprasidone (80 or $160 \mathrm{mg}$ ), $75 \%, 50 \%$ and $47 \%$ of participants completed the study, respectively [81]. A meta-analysis of second generation agents, not including ziprasidone, for augmentation therapy in major depressive disorder demonstrated an odds ratio of 1.30 (95\% CI 1.09, 1.57) for discontinuation for any reason [75].

\section{Dosing and switching challenges and solutions Dosing}

Evidence informed clinical experience suggests that optimal dosing of ziprasidone in first episode patients appears to be in the range of $80-160 \mathrm{mg} / \mathrm{d}$, for chronic schizophrenia 120-160 mg/d, for bipolar mania 120$160 \mathrm{mg} / \mathrm{d}$. While evidence of benefit in major depression is lacking, when tried, a lower dose of $20-80 \mathrm{mg} / \mathrm{d}$ is recommended.

Dosing should be started at $40 \mathrm{mg}$ twice daily with meals for inpatients and 20 to $40 \mathrm{mg}$ twice daily for outpatients. For example, a suggested schedule for an early psychosis outpatient is: Day 1: $20 \mathrm{mg}$ AM, $40 \mathrm{mg}$ PM; Day 2: $40 \mathrm{mg}$ AM, $60 \mathrm{mg}$ PM, Day 3: $60 \mathrm{mg}$ AM, $60 \mathrm{mg}$ PM, then reassess. The second dose of the day should be taken with the last meal of the day, and patients should be informed about the importance of consuming $500 \mathrm{kcal}$ of food with each dose of their ziprasidone.

The traditional approach to dosing antipsychotic medications is to start at a low dose and gradually titrate upward based on patient tolerance and response. This approach has been challenged of late with findings that a more rapid titration, for example with quetiapine, may increase the chance for successful long-term therapy $[187,188]$. This may also apply to ziprasidone $[185,189]$. A pooled re-analysis of discontinuation rates at or 


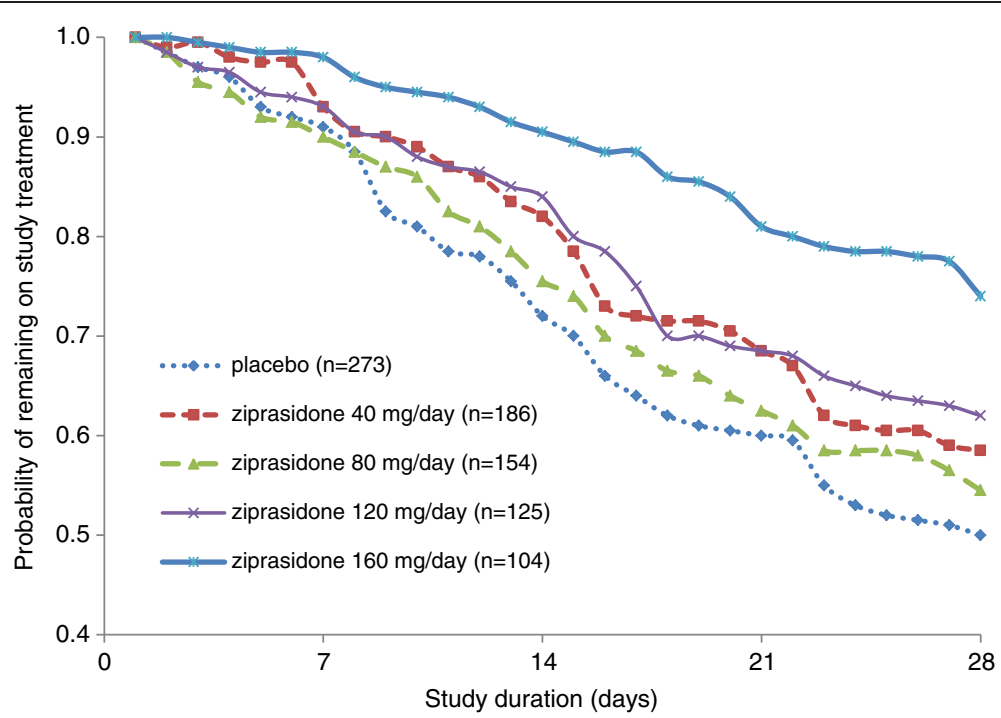

Figure 2 All-cause discontinuation survival curves by ziprasidone dose. Reproduced with permission [185].

before 4 weeks of treatment was conducted based on 4 placebo-controlled, fixed-dose studies $(\mathrm{n}=842)$ of ziprasidone. The rate of all cause discontinuation was lowest with ziprasidone at its highest dose, primarily driven by its greater efficacy. The respective rates of discontinuations for all reasons, lack of efficacy, and adverse effects by dose were: placebo: $50 \%, 31 \%, 2 \%$; $40 \mathrm{mg} / \mathrm{d}: 41 \%, 24 \%, 2 \% ; 80 \mathrm{mg} / \mathrm{d}: 46 \%, 22 \%, 2 \%$; $120 \mathrm{mg} / \mathrm{d}: 38 \%, 18 \%, 7 \%$; and $160 \mathrm{mg} / \mathrm{d}: 27 \%, 11 \%, 4 \%$. Figure 2 illustrates greater treatment persistence is detectable as early as 7 to 14 days when the higher target dose of $160 \mathrm{mg} / \mathrm{d}$ is prescribed.

Ziprasidone dosing recommendations vary depending on the diagnosis and age of the patient and should also be sensitive to patient-specific safety, tolerability and efficacy issues inferred from past treatment response and medical considerations $[9,109]$. For dose guidance refer to Table 3.

A notable challenge to initiating ziprasidone therapy is its association with activation and insomnia early in

Table 3 Ziprasidone dosing recommendations* $[9,109,163]$

\begin{tabular}{llll}
\hline & Start dose \& titration rate & Target dose range & Maximum dose \\
\hline Schizophrenia (adults) & $20-40 \mathrm{mg}$ twice daily & $60-80 \mathrm{mg}$ twice daily & $100 \mathrm{mg}$ twice daily \\
& $\uparrow$ every 1-3 days & \\
Bipolar mania (adults) & $40 \mathrm{mg}$ twice daily & $60-80 \mathrm{mg}$ twice daily & \\
& $\uparrow$ every 1-2 days & \\
Elderly & No differences in the pharmacokinetics of ziprasidone were observed in a small study involving healthy \\
& elderly patients. A limited number of elderly with schizophrenia were exposed to ziprasidone in clinical \\
& trials who demonstrated similar tolerability as adults. These findings suggest that reduced dosing may not \\
& be necessary unless other considerations are present. Ziprasidone, like other atypical antipsychotics, is not \\
& indicated for elderly patients with dementia due the elevated risk of death.
\end{tabular}

Children

There is limited experience with ziprasidone in children under clinical trial conditions, as such data to support its safety and efficacy at any dose is insufficient. Mean dose is one small RCT in children (11.5 y) with tics was $\sim 30 \mathrm{mg} /$ day. In a larger RCT of older children \& adolescents (13.6 y) with bipolar disorder, the mean dose was $120 \mathrm{mg} /$ day in those weighing $>45 \mathrm{~kg}$.

Special populations

Dosage adjustments are generally not required on the basis of gender, race, or renal function. Dose reduction of $40-50 \%$ is recommended in the presence of severe hepatic insufficiency and of $20-30 \%$ in adolescents, first episode psychosis, organic brain syndrome, bipolar maintenance, underweight, and Asian ethnicity.

Potent inhibitors and inducers of CYP3A4 Dose modification of ziprasidone may be warranted. Pharmacokinetic studies demonstrate the potential for an estimated 30-40\% change in systemic exposure to ziprasidone when co-administered with potent CYP3A4 inhibitors (e.g., clarithromycin, protease inhibitors, ketoconazole) and inducers (e.g., carbamazepine, St John's wort). 
the course. In general, slower, more cautious titrations have been associated with poorer outcomes. As such, this panel recommends a more rapid titration schedule to target doses and, when necessary, the limited-term use of anxiolytics to support treatment initiation (e.g., lorazepam 1-2 mg/day as needed $\times 7$ days). Patients should be advised that they might experience some restlessness or agitation, which frequently subsides with dosage escalation and time or may benefit from a short course of a benzodiazepine. If the presentation is more fitting with a diagnosis of antipsychotic-induced akathisia, rapid dosage escalation is not recommended. Rather, antiakathisic treatment such as propranolol can be considered and dosage escalation continued if akathisia subsides.

\section{Switching}

The method of switching between antipsychotics varies, however the most commonly applied method is the overlapping switch. In doing so, there are multiple factors to consider before embarking on a switch in antipsychotic therapy that involves ziprasidone [190-192]. These include the reason for the switch (e.g., lack of response, intolerance, non-adherence), the pharmacologies of the antipsychotics being stopped and started (e.g., high or low antagonist potency at dopamine, histamine, and muscarinic receptors), and dosing history (e.g., duration, daily dose).

Clinical experience suggests that higher doses of a replacement antipsychotic are usually needed when previous antipsychotics have proven inadequately effective and that lower doses are indicated with a history of intolerance to previous agents. These experience-based principles apply to dosing targets when switching to ziprasidone. Also, when the pharmacologies of the outgoing and incoming antipsychotic are at odds with each other (e.g., high vs. low potency at dopamine, histamine, or muscarinic receptors) a more careful switch is warranted. For example, when switching from olanzapine, quetiapine, or clozapine to ziprasidone, an excessively rapid transition may be associated with activation and signs and symptoms of cholinergic rebound due to the rapid loss of the antihistaminc and/or anticholinergic effects. Attention to sleep hygiene measures (e.g., avoid late-day use of caffeine and other stimulants, rise at the same time each day, etc.) and short-term use of sedatives can help address this when it is necessary to reduce the doses of these drugs quickly. D2 related adverse effects, such as EPS, may also worsen transiently due to excessive D2 blockade if down titration of the current antipsychotic is too slow. This latter issue is especially of concern when switching between risperidone, paliperidone, or other potent D2 antagonists with longer half-lives and ziprasidone.

\section{Conclusion}

The available literature and discussions of clinical experience reviewed in this paper support the use of ziprasidone in schizophrenia and bipolar mania. There is less information available to support its use in other indications including depression and anxiety or for special groups including children, youth, and elderly. Ziprasidone's main advantages over other antipsychotics include its attractive metabolic effects profile. Clinicians should prioritize ziprasidone for patients with pre-existing metabolic issues (e.g., obesity, dyslipidemia, impaired glucose tolerance), patients with metabolic adverse effects to other antipsychotics, and for patients wishing to mitigate the risk for metabolic adverse effects when considering their antipsychotic options. Patients should be informed that ziprasidone has a high rate of early treatment discontinuation, primarily due to a lack of efficacy and/or adverse effects, and that the risk for this is lower with some but not all other antipsychotics. A remarkable feature is that ziprasidone clearly needs to be taken with food, an issue that may underlie a proportion of treatment failures in trials and clinical practice. As with other antipsychotics, optimal dosing of ziprasidone has evolved with experience and new clinical information. To maximize ziprasidone's benefits and limit early intolerance, we advocate targeting the high end of the dosing range of ziprasidone along with the limited term use of a benzodiazepine to manage the not uncommon experience of activation or agitation with treatment initiation.

\section{Abbreviations}

BMI: Body mass index; CANMAT: Canadian Network for Mood and Anxiety Treatments; CATIE: Clinical Antipsychotic Trials of Intervention Effectiveness; CGI: Clinical Global Impression; ECG: Electrocardiogram; EPS: Extrapyramidal Symptoms; EUFEST: European First Episode Schizophrenia Trial; HAMD: Hamilton Rating Scale for Depression; MADRS: Montgomery-Asberg Depression Rating Scale; MDD: Major Depressive Disorder; MRS: Mania Rating Scale; NPI: Neuropsychiatric Inventory; PANSS: Positive and Negative

Syndrome Scale; QLS: Quality of Life Scale; SSRI: Selective Serotonin Reuptake Inhibitor; TdP: Torsades de pointes; WFSBP: World Federation of Societies of Biological Psychiatry.

\section{Competing interests}

Dr. Andrea Murphy, Dr. Stan Kutcher, Dr. Carlo Carandang, and Dr. Jorge Soni declare that they have no competing interests.

Dr. David Gardner has been involved with the advisory board for JanssenOrtho and has received education grant funding from Pfizer for this project. Dr. Serge Beaulieu has been a speaker for Astra Zeneca, Biovail, Bristol Myers Squibb (BMS), Eli Lilly, GlaxoSmithKline (GSK), Janssen-Ortho, Lundbeck,

Organon, Oryx, Pfizer, Wyeth. He has acted on the advisory board and/or as a consultant for Astra Zeneca, BMS, Eli Lilly, GSK, Janssen-Ortho, Lundbeck, Oryx, Otsuka, Schering-Plough Merck, Pfizer. He has also received research support from Astra Zeneca, Biovail, BMS, Eli Lilly, Janssen-Ortho, Lundbeck, Merck-Frosst, Novartis, Pfizer, and Servier.

Dr. Alain Labelle has been involved with advisory boards for Pfizer and has been a speaker for Pfizer

Dr. Pierre Lalonde has been involved with advisory boards for BMS and Pfizer, and has also been a speaker for BMS and Pfizer. 
Dr. Ashok Malla has received grant support from Astra Zeneca, Pfizer, BMS and Janssen Ortho. He has been involved with the advisory board and acted as speaker honoraria for Janssen, BMS, Pfizer, Astra-Zeneca, Sunovion, Lundbeck, and Wyeth.

Dr. Heather Milliken has been involved as a speaker, member of advisory board, clinical trals and/or educational grants for Janssen-Ortho, Lundbeck, Otsuka, Pfizer, Roche, Sunovion

Dr. Claire O'Donovan has received Research Funding from Elan Pharma, Pfizer, Cephalon, Brain Cells Inc. She has also been involved with the advisory boards for Astra Zeneca, Pfizer, BMS, Sunovion, Lundbeck, and Servier.

Dr. Ayal Schaffer has been involed with the advisory board and speaker's bureau for and has received research grants from AstraZeneca, BMS, Canadian Network for Mood and Anxiety Treatments, Eli Lilly, Lundbeck, and Pfizer.

Dr. VH Taylor has been a speaker for Lilly, Pfizer, Lundbeck, BMS and Allergan and has received grant funding from BMS.

Dr. Richard Williams has received research, ad boards, and travel support from Pfizer, Janssen-Ortho, Roche, Mylan, Lundbeck, and BMS.

\section{Authors' contributions}

All fourteen authors were convened on April 16, 2010 in order to discuss and synthesize suggestions for the clinical use of ziprasidone based on current research and clinical experiences. DG and SK served as the co-chairs for the meeting and AM and DG led the development of the manuscript. Members were delegated a specific clinical area to critically analyze and present at the meeting. During the development of this manuscript, all members were provided with two opportunities for critical and constructive feedback. This manuscript, drafted by AM and DG, represents a synthesis of information from individual presentations, collective discussions, an extensive examination of the evidence base, and feedback from all panel members. All authors read and approved the final manuscript.

\section{Acknowledgments}

This consensus project was supported by a grant from Pfizer Canada who is the manufacturer of ziprasidone. Other than providing funding for the consensus review Pfizer had no involvement in the project. No employee of Pfizer saw any content of the manuscript prior to its publications. We would like to thank Dave Carter of Multidimensional Healthcare as well as Christina Clark and Kathryn Landry for their logistical and research support throughout the project.

\section{Author details}

${ }^{1}$ Department of Psychiatry, Dalhousie University, Halifax, NS, Canada.

${ }^{2}$ Department of Psychiatry, McGill University, Montreal, QC, Canada.

${ }^{3}$ Department of Psychiatry, University of Ottawa, Ottawa, ON, Canada.

${ }^{4}$ Centre de recherche Fernand-Seguin de I'Hôpital Louis-H. Lafontaine, Montreal, QC, Canada. ${ }^{5}$ Department of Psychiatry, University of Toronto, Toronto, ON, Canada. ${ }^{6}$ Department of Psychiatry, University of British Columbia, Vancouver, BC, Canada.

Received: 13 November 2012 Accepted: 14 January 2013 Published: 24 January 2013

\section{References}

1. Procyshyn RM, Honer WG, Wu TK, Ko RW, Mclsaac SA, Young AH, Johnson $J$, Barr AM: Persistent antipsychotic polypharmacy and excessive dosing in the community psychiatric treatment setting: a review of medication profiles in 435 Canadian outpatients. J Clin Psychiatry 2010, 71(5):566-573.

2. Sproule BA, Lake J, Mamo DC, Uchida H, Mulsant BH: Are antipsychotic prescribing patterns different in older and younger adults? a survey of 1357 psychiatric inpatients in toronto. Can J Psychiatry 2010, 55(4):248-254.

3. Verdoux H, Tournier M, Begaud B: Antipsychotic prescribing trends: a review of pharmaco-epidemiological studies. Acta Psychiatr Scand 2010, 121(1):4-10.

4. Kutcher S, Brooks SJ, Gardner DM, Honer B, Kopala L, Labelle A, Lalonde P, Malla A, Milliken H, Soni J, Williams R: Expert Canadian consensus suggestions on the rational, clinical use of ziprasidone in the treatment of schizophrenia and related psychotic disorders. Neuropsychiatr Dis Treat 2005, 1(2):89-108.
5. Pfizer Canada: Community investment: funding criteria and guidelines. http:// www.pfizer.ca/en/healthier_communities/request_for_support/.

6. DeLeon A, Patel NC, Crismon ML: Aripiprazole: a comprehensive review of its pharmacology, clinical efficacy, and tolerability. Clin Ther 2004, 26(5):649-666.

7. Schmidt AW, Lebel LA, Howard HR Jr, Zorn SH: Ziprasidone: a novel antipsychotic agent with a unique human receptor binding profile. Eur J Pharmacol 2001, 425(3):197-201.

8. Seeger TF, Seymour PA, Schmidt AW, Zorn SH, Schulz DW, Lebel LA, McLean S, Guanowsky V, Howard HR, Lowe JA III: Ziprasidone (CP-88,059): a new antipsychotic with combined dopamine and serotonin receptor antagonist activity. J Pharmacol Exp Ther 1995, 275(1):101-113.

9. Gardner DM, Murphy AL, O'Donnell H, Centorrino F, Baldessarini RJ: International consensus study of antipsychotic dosing. Am J Psychiatry 2010, 167(6):686-693.

10. Bristol-Myers Squibb Canada: Abilify Product Monograph. Montreal (QC) Bristol-Myers Squibb; 2011.

11. Schotte A, Janssen PF, Gommeren W, Luyten WH, Van Gompel P, Lesage AS, De Loore K, Leysen JE: Risperidone compared with new and reference antipsychotic drugs: in vitro and in vivo receptor binding. Psychopharmacology (Berl) 1996, 124(1-2):57-73.

12. Tatsumi M, Jansen $K$, Blakely RD, Richelson E: Pharmacological profile of neuroleptics at human monoamine transporters. Eur J Pharmacol 1999, 368(2-3):277-283.

13. Mazei MS, Pluto CP, Kirkbride B, Pehek EA: Effects of catecholamine uptake blockers in the caudate-putamen and subregions of the medial prefrontal cortex of the rat. Brain Res 2002, 936(1-2):58-67.

14. Pfizer Canada Inc: Zeldox Product Monograph. In Edited by Anonymous. Kirkland, Quebec: Pfizer Canada Inc; 2010.

15. Stahl SM, Shayegan DK: The psychopharmacology of ziprasidone: receptor-binding properties and real-world psychiatric practice. J Clin Psychiatry 2003, 64(Suppl 19):6-12.

16. Altar CA, Wasley AM, Neale RF, Stone GA: Typical and atypical antipsychotic occupancy of D2 and S2 receptors: an autoradiographic analysis in rat brain. Brain Res Bull 1986, 16(4):517-525.

17. Meltzer HY: The mechanism of action of novel antipsychotic drugs. Schizophr Bull 1991, 17(2):263-287.

18. Meyer JM, Nasrallah HA, McEvoy JP, Goff DC, Davis SM, Chakos M, Patel JK, Keefe RS, Stroup TS, Lieberman JA: The Clinical Antipsychotic Trials of Intervention Effectiveness (CATIE) schizophrenia trial: clinical comparison of subgroups with and without the metabolic syndrome. Schizophr Res 2005, 80(1):9-18.

19. Bremner JD, Vythilingam M, Ng CK, Vermetten E, Nazeer A, Oren DA, Berman RM, Charney DS: Regional brain metabolic correlates of alphamethylparatyrosine-induced depressive symptoms: implications for the neural circuitry of depression. JAMA 2003, 289(23):3125-3134.

20. Bymaster FP, Katner JS, Nelson DL, Hemrick-Luecke SK, Threlkeld PG, Heiligenstein JH, Morin SM, Gehlert DR, Perry KW: Atomoxetine increases extracellular levels of norepinephrine and dopamine in prefrontal cortex of rat: a potential mechanism for efficacy in attention deficit/ hyperactivity disorder. Neuropsychopharmacology 2002, 27(5):699-711.

21. Tecott LH, Sun LM, Akana SF, Strack AM, Lowenstein DH, Dallman MF, Julius D: Eating disorder and epilepsy in mice lacking 5 -HT2C serotonin receptors. Nature 1995, 374(6522):542-546.

22. Kroeze WK, Hufeisen SJ, Popadak BA, Renock SM, Steinberg S, Ernsberger P, Jayathilake K, Meltzer HY, Roth BL: H1-histamine receptor affinity predicts short-term weight gain for typical and atypical antipsychotic drugs. Neuropsychopharmacology 2003, 28(3):519-526.

23. Mamo D, Kapur S, Shammi CM, Papatheodorou G, Mann S, Therrien F, Remington G: A PET study of dopamine D2 and serotonin 5-HT2 receptor occupancy in patients with schizophrenia treated with therapeutic doses of ziprasidone. Am J Psychiatry 2004, 161(5):818-825.

24. Lincoln J, Stewart ME, Preskorn SH: How sequential studies inform drug development: evaluating the effect of food intake on optimal bioavailability of ziprasidone. J Psychiatr Pract 2010, 16(2):103-114.

25. Citrome L: Using oral ziprasidone effectively: the food effect and doseresponse. Adv Ther 2009, 26(8):739-748.

26. Canadian Psychiatric Association: Clinical practice guidelines. Treatment of schizophrenia. Can J Psychiatry 2005, 50:s7-s57.

27. Komossa K, Rummel-Kluge C, Hunger H, Schwarz S, Bhoopathi PS, Kissling W, Leucht S: Ziprasidone versus other atypical antipsychotics for schizophrenia. Cochrane Database Syst Rev 2009, 4(4):CD006627. 
28. Sacchetti E, Galluzzo A, Valsecchi P, Romeo F, Gorini B, Warrington L, INITIATE Study Group: Ziprasidone vs clozapine in schizophrenia patients refractory to multiple antipsychotic treatments: the MOZART study. Schizophr Res 2009, 110(1-3):80-89.

29. Kahn RS, Fleischhacker WW, Boter H, Davidson M, Vergouwe Y, Keet IP, Gheorghe MD, Rybakowski JK, Galderisi S, Libiger J, Hummer M, Dollfus S, Lopez-Ibor JJ, Hranov LG, Gaebel W, Peuskens J, Lindefors N, Riecher-Rossler A, Grobbee DE, EUFEST study group: Effectiveness of antipsychotic drugs in first-episode schizophrenia and schizophreniform disorder: an open randomised clinical trial. Lancet 2008, 371(9618):1085-1097.

30. Ratner Y, Gibel A, Yorkov V, Ritsner MS: Effectiveness, safety, and tolerability of ziprasidone for treating schizophrenia patients undergoing usual care: a 12-month, open-label, flexible-dose, naturalistic observational trial. Prog Neuropsychopharmacol Biol Psychiatry 2007, 31(7):1401-1409.

31. Addington DE, Labelle A, Kulkarni J, Johnson G, Loebel A, Mandel FS: A comparison of ziprasidone and risperidone in the long-term treatment of schizophrenia: a 44-week, double-blind, continuation study. Can J Psychiatry 2009, 54(1):46-54.

32. Loebel AD, Khanna S, Rajadhyaksha S, Siu CO, Giller E, Potkin SG Ziprasidone in treatment-resistant schizophrenia: a 52-week, open-label continuation study. J Clin Psychiatry 2007, 68(9):1333-1338.

33. Potkin SG, Weiden PJ, Loebel AD, Warrington LE, Watsky EJ, Siu CO: Remission in schizophrenia: 196-week, double-blind treatment with ziprasidone vs. haloperidol. Int J Neuropsychopharmacol 2009, 12(9):1233-1248.

34. Stahl SM, Malla A, Newcomer JW, Potkin SG, Weiden PJ, Harvey PD, Loebel A, Watsky E, Siu CO, Romano S: A post hoc analysis of negative symptoms and psychosocial function in patients with schizophrenia: a 40-week randomized, double-blind study of ziprasidone versus haloperidol followed by a 3-year double-blind extension trial. J Clin Psychopharmacol 2010, 30(4):425-430.

35. Boter H, Peuskens J, Libiger J, Fleischhacker WW, Davidson M, Galderisi S, Kahn RS, EUFEST study group: Effectiveness of antipsychotics in firstepisode schizophrenia and schizophreniform disorder on response and remission: an open randomized clinical trial (EUFEST). Schizophr Res 2009, 115(2-3):97-103.

36. Boter H, Derks EM, Fleischhacker WW, Davidson M, Kahn RS, EUFEST Study Group: Generalizability of the results of efficacy trials in first-episode schizophrenia: comparisons between subgroups of participants of the European First Episode Schizophrenia Trial (EUFEST). J Clin Psychiatry 2010, 71(1):58-65.

37. Davidson M, Galderisi S, Weiser M, Werbeloff N, Fleischhacker WW, Keefe RS, Boter H, Keet IP, Prelipceanu D, Rybakowski JK, Libiger J, Hummer M, Dollfus S, Lopez-Ibor JJ, Hranov LG, Gaebel W, Peuskens J, Lindefors N, RiecherRossler A, Kahn RS: Cognitive effects of antipsychotic drugs in firstepisode schizophrenia and schizophreniform disorder: a randomized, open-label clinical trial (EUFEST). Am J Psychiatry 2009, 166(6):675-682.

38. Galderisi S, Davidson M, Kahn RS, Mucci A, Boter H, Gheorghe MD, Rybakowski JK, Libiger J, Dollfus S, Lopez-Ibor JJ, Peuskens J, Hranov LG, Fleischhacker WW, EUFEST group: Correlates of cognitive impairment in first episode schizophrenia: the EUFEST study. Schizophr Res 2009, 115(2-3):104-114.

39. Goldberg TE, Gomar Jj: Targeting cognition in schizophrenia research: from etiology to treatment. Am J Psychiatry 2009, 166(6):631-634.

40. Keefe RS, Bilder RM, Davis SM, Harvey PD, Palmer BW, Gold JM, Meltzer HY, Green MF, Capuano G, Stroup TS, McEvoy JP, Swartz MS, Rosenheck RA, Perkins DO, Davis CE, Hsiao JK, Lieberman JA, CATIE Investigators, Neurocognitive Working Group: Neurocognitive effects of antipsychotic medications in patients with chronic schizophrenia in the CATIE Trial. Arch Gen Psychiatry 2007, 64(6):633-647.

41. Foussias $G$, Remington $G$ : Antipsychotics and schizophrenia: from efficacy and effectiveness to clinical decision-making. Can J Psychiatry 2010, 55(3):117-125.

42. Gjerden P, Slordal L, Bramness JG: Prescription persistence and safety of antipsychotic medication: a national registry-based 3-year follow-up. Eur J Clin Pharmacol 2010, 66(9):911-917.

43. Goodwin GM, Consensus Group of the British Association for Psychopharmacology: Evidence-based guidelines for treating bipolar disorder: revised second edition-recommendations from the British Association for Psychopharmacology. J Psychopharmacol 2009, 23(4):346-388.

44. Perlis RH, Welge JA, Vornik LA, Hirschfeld RM, Keck PE Jr: Atypical antipsychotics in the treatment of mania: a meta-analysis of randomized, placebo-controlled trials. J Clin Psychiatry 2006, 67(4):509-516.
45. Grunze H, Vieta E, Goodwin GM, Bowden C, Licht RW, Moller HJ, Kasper S: The World Federation of Societies of Biological Psychiatry (WFSBP) guidelines for the biological treatment of bipolar disorders: update 2009 on the treatment of acute mania. World J Biol Psychiatry 2009, 10(2):85-116.

46. Grunze H, Vieta E, Goodwin GM, Bowden C, Licht RW, Moller HJ, Kasper S, WFSBP Task Force On Treatment Guidelines For Bipolar Disorders: The World Federation of Societies of Biological Psychiatry (WFSBP) guidelines for the biological treatment of bipolar disorders: update 2010 on the treatment of acute bipolar depression. World J Biol Psychiatry 2010, 11(2):81-109.

47. Tohen M, Vieta E, Calabrese J, Ketter TA, Sachs G, Bowden C, Mitchell PB, Centorrino F, Risser R, Baker RW, Evans AR, Beymer K, Dube S, Tollefson GD, Breier A: Efficacy of olanzapine and olanzapine-fluoxetine combination in the treatment of bipolar I depression. Arch Gen Psychiatry 2003, 60(11):1079-1088.

48. Thase ME, Macfadden W, Weisler RH, Chang W, Paulsson B, Khan A, Calabrese JR, BOLDER II Study Group: Efficacy of quetiapine monotherapy in bipolar I and II depression: a double-blind, placebo-controlled study (the BOLDER II study). J Clin Psychopharmacol 2006, 26(6):600-609.

49. Calabrese JR, Keck PE Jr, Macfadden W, Minkwitz M, Ketter TA, Weisler RH, Cutler AJ, McCoy R, Wilson E, Mullen J: A randomized, double-blind, placebo-controlled trial of quetiapine in the treatment of bipolar I or II depression. Am J Psychiatry 2005, 162(7):1351-1360.

50. Keck PE Jr, Calabrese JR, Mclntyre RS, McQuade RD, Carson WH, Eudicone JM, Carlson BX, Marcus RN, Sanchez R, Aripiprazole Study Group: Aripiprazole monotherapy for maintenance therapy in bipolar I disorder: a 100-week, double-blind study versus placebo. J Clin Psychiatry 2007, 68(10):1480-1491.

51. Nierenberg AA, Ostacher MJ, Calabrese JR, Ketter TA, Marangell LB, Miklowitz DJ, Miyahara S, Bauer MS, Thase ME, Wisniewski SR, Sachs GS: Treatment-resistant bipolar depression: a STEP-BD equipoise randomized effectiveness trial of antidepressant augmentation with lamotrigine, inositol, or risperidone. Am J Psychiatry 2006, 163(2):210-216.

52. Lombardo I, Sachs G, Kolluri S, Kremer C, Yang R: Two 6-week, randomized, double-blind, placebo-controlled studies of ziprasidone in outpatients with bipolar I depression: did baseline characteristics impact trial outcome? J Clin Psychopharmacol 2012, 32(4):470-478.

53. Pfizer Inc: A six-week, double-blind, multicenter, placebo controlled study evaluating the efficacy and safety of flexible doses of oral ziprasidone as addon, adjunctive therapy with lithium, valproate, or lamotrigine in bipolar 1 depression. http://www.clinicaltrials.gov/ct2/show/study/NCT00483548.

54. Pfizer Inc.: A six-week, randomized, double-blind, multicenter, fixed-flexible dose, placebo-controlled study evaluation the efficacy and safety of oral ziprasidone in outpatients with bipolar / depression. http://www.clinicaltrials.gov/ct2/ show/study/NCT00141271.

55. Sachs GS, Ice KS, Chappell PB, Schwartz JH, Gurtovaya O, Vanderburg DG, Kasuba B: Efficacy and safety of adjunctive oral ziprasidone for acute treatment of depression in patients with bipolar I disorder: a randomized, double-blind, placebo-controlled trial. J Clin Psychiatry 2011, 72(10):1413-1422.

56. Patkar A, Gilmer W, Pae CU, Vohringer PA, Ziffra M, Pirok E, Mulligan M, Filkowski MM, Whitham EA, Holtzman NS, Thommi SB, Logvinenko T, Loebel A, Masand P, Ghaemi SN: A 6 week randomized double-blind placebocontrolled trial of ziprasidone for the acute depressive mixed state. PLoS One 2012, 7(4):e34757.

57. Soares-Weiser K, Bravo Vergel Y, Beynon S, Dunn G, Barbieri M, Duffy S, Geddes J, Gilbody S, Palmer S, Woolacott N: A systematic review and economic model of the clinical effectiveness and cost-effectiveness of interventions for preventing relapse in people with bipolar disorder. Health Technol Assess 2007, 11(39):206.

58. Cipriani A, Rendell J, Geddes JR: Olanzapine in the long-term treatment of bipolar disorder: a systematic review and meta-analysis. J Psychopharmacol 2010, 24(12):1729-1738.

59. Scherk H, Pajonk FG, Leucht S: Second-generation antipsychotic agents in the treatment of acute mania: a systematic review and meta-analysis of randomized controlled trials. Arch Gen Psychiatry 2007, 64(4):442-455.

60. Yildiz A, Vieta E, Leucht S, Baldessarini RJ: Efficacy of antimanic treatments: meta-analysis of randomized, controlled trials. Neuropsychopharmacology 2011, 36(2):375-389.

61. Yatham LN, Kennedy SH, Schaffer A, Parikh SV, Beaulieu S, O'Donovan C, MacQueen G, McIntyre RS, Sharma V, Ravindran A, Young LT, Young AH, Alda M, Milev R, Vieta E, Calabrese JR, Berk M, Ha K, Kapczinski F: Canadian Network for Mood and Anxiety Treatments (CANMAT) and International Society for Bipolar Disorders (ISBD) collaborative update of CANMAT 
guidelines for the management of patients with bipolar disorder: update 2009. Bipolar Disord 2009, 11(3):225-255.

62. Keck PE Jr, Versiani M, Potkin S, West SA, Giller E, Ice K, Ziprasidone in Mania Study Group: Ziprasidone in the treatment of acute bipolar mania: a three-week, placebo-controlled, double-blind, randomized trial. Am J Psychiatry 2003, 160(4):741-748.

63. Potkin SG, Keck PE Jr, Segal S, Ice K, English P: Ziprasidone in acute bipolar mania: a 21-day randomized, double-blind, placebo-controlled replication trial. J Clin Psychopharmacol 2005, 25(4):301-310.

64. Gardner DM, Murphy AL: Gardner's effect size illustrator. http://esi.medicine.dal.ca/.

65. Vieta E, Ramey T, Keller D, English PA, Loebel AD, Miceli J: Ziprasidone in the treatment of acute mania: a 12-week, placebo-controlled, haloperidol-referenced study. J Psychopharmacol 2010, 24(4):547-558.

66. Ketter TA, Agid O, Kapur S, Loebel A, Siu CO, Romano SJ: Rapid antipsychotic response with ziprasidone predicts subsequent acute manic/mixed episode remission. J Psychiatr Res 2010, 44(1):8-14.

67. Stahl S, Lombardo I, Loebel A, Mandel FS: Efficacy of ziprasidone in dysphoric mania: pooled analysis of two double-blind studies. J Affect Disord 2010, 122(1-2):39-45.

68. Weisler R, Dunn J, English P: Adjunctive ziprasidone for acute bipolar mania: randomized, placebo-controlled trial [abstract]. Monte-Carlo, Monaco: 4th International Forum on Mood and Anxiety Disorders; 2003.

69. Bowden CL, Vieta E, Ice KS, Schwartz JH, Wang PP, Versavel M: Ziprasidone plus a mood stabilizer in subjects with bipolar I disorder: a 6-month, randomized, placebo-controlled, double-blind trial. J Clin Psychiatry 2010, 71(2):130-137.

70. Leucht S, Corves C, Arbter D, Engel RR, Li C, Davis JM: Second-generation versus first-generation antipsychotic drugs for schizophrenia: a metaanalysis. Lancet 2009, 373(9657):31-41.

71. Massachusetts General Hospital: A 12-week, placebo controlled trial of ziprasidone as monotherapy for major depressive disorder. http://www. clinicaltrials.gov/ct2/show/study/NCT00555997.

72. Cedars-Sinai Medical Center: Treatment of major depressive disorder (MDD) with ziprasidone. http://www.clinicaltrials.gov/ct2/show/study/NCT00657592.

73. Massachusetts General Hospital: Ziprasidone augmentation of SSRIs for patients with major depressive disorder (MDD) that do not sufficiently respond to treatment with SSRIs. http://www.clinicaltrials.gov/ct2/show/study/ NCT00633399.

74. Duke University: Ziprasidone vs. sertraline/haloperidol in psychotic depression. http://www.clinicaltrials.gov/ct2/show/NCT00340379.

75. Lam RW, Kennedy SH, Grigoriadis S, Mclntyre RS, Milev R, Ramasubbu R, Parikh SV, Patten SB, Ravindran AV, Canadian Network for Mood and Anxiety Treatments (CANMAT): Canadian Network for Mood and Anxiety Treatments (CANMAT) clinical guidelines for the management of major depressive disorder in adults. III. Pharmacotherapy. J Affect Disord 2009, 117(Suppl 1):S26-S43.

76. Nelson JC, Papakostas Gl: Atypical antipsychotic augmentation in major depressive disorder: a meta-analysis of placebo-controlled randomized trials. Am J Psychiatry 2009, 166(9):980-991.

77. Bauer M, Pretorius HW, Constant EL, Earley WR, Szamosi J, Brecher M: Extended-release quetiapine as adjunct to an antidepressant in patients with major depressive disorder: results of a randomized, placebocontrolled, double-blind study. J Clin Psychiatry 2009, 70(4):540-549.

78. Komossa K, Depping AM, Gaudchau A, Kissling W, Leucht S: Secondgeneration antipsychotics for major depressive disorder and dysthymia. Cochrane Database Syst Rev 2010, 12:CD008121.

79. Barbee JG, Conrad EJ, Jamhour NJ: The effectiveness of olanzapine, risperidone, quetiapine, and ziprasidone as augmentation agents in treatment-resistant major depressive disorder. J Clin Psychiatry 2004, 65(7):975-981.

80. Papakostas GI, Petersen TJ, Nierenberg AA, Murakami JL, Alpert JE, Rosenbaum JF, Fava M: Ziprasidone augmentation of selective serotonin reuptake inhibitors (SSRIs) for SSRI-resistant major depressive disorder. J Clin Psychiatry 2004, 65(2):217-221.

81. Dunner DL, Amsterdam JD, Shelton RC, Loebel A, Romano SJ: Efficacy and tolerability of adjunctive ziprasidone in treatment-resistant depression: a randomized, open-label, pilot study. J Clin Psychiatry 2007, 68(7):1071-1077.

82. Moeller O, Evers S, Deckert J, Baune BT, Dannlowski U, Nguyen DH, Arolt V, Hetzel G: The impact of ziprasidone in combination with sertraline on visually-evoked event-related potentials in depressed patients with psychotic features. Prog Neuropsychopharmacol Biol Psychiatry 2007 31(7):1440-1443.
83. Haddad PM, Sharma SG: Adverse effects of atypical antipsychotics: differential risk and clinical implications. CNS Drugs 2007, 21(11):911-936.

84. Citrome L: Drug safety evaluation of ziprasidone. Expert Opin Drug Saf 2011, 10(3):437-448

85. Kaushik S, Maccabee N, Kaushik S, Lindenmayer JP: Activation induced by high-dose ziprasidone: a case report. J Clin Psychiatry 2009, 70(9):1326-1327.

86. Park JM, Park L, Prager LM: Emergency Psychiatry. In Massachusetts General Hospital Comprehensive Clinical Psychiatry. 1st edition. Edited by Stern TA, Rosenbaum JF. Philadelphia, PA: Mosby; 2008.

87. Keating AM, Aoun SL, Dean CE: Ziprasidone-associated mania: a review and report of 2 additional cases. Clin Neuropharmacol 2005, 28(2):83-86.

88. Shah RR: Interpretation of Clinical ECG Data: Understanding the Risk From Non-antiarrhythmic Drugs. In Cardiac Safety of Noncardiac Drugs: Practical Guidelines for Clinical Research and Drug Development. Edited by Morganroth J, Gussak I. Totowa, NJ: Human Press Inc; 2005:259-298.

89. Harrigan EP, Miceli JJ, Anziano R, Watsky E, Reeves KR, Cutler NR, Sramek J, Shiovitz T, Middle M: A randomized evaluation of the effects of six antipsychotic agents on QTc, in the absence and presence of metabolic inhibition. J Clin Psychopharmacol 2004, 24(1):62-69.

90. Miceli JJ, Tensfeldt TG, Shiovitz T, Anziano R, O'Gorman C, Harrigan RH: Effects of oral ziprasidone and oral haloperidol on QTc interval in patients with schizophrenia or schizoaffective disorder. Pharmacotherapy 2010, 30(2):127-135.

91. Eker SS, Sarandol A, Akkaya C, Sivrioglu EY, Kirli S: The potential relationship between QTc interval prolongation and ziprasidone treatment: three cases. J Psychopharmacol 2009, 23(8):993-996.

92. Rocha FL, Hara C, Ramos MG, Kascher GG, Santos MA, de Oliveira Lanca G, Magalhaes Scoralick F: An exploratory open-label trial of ziprasidone for the treatment of behavioral and psychological symptoms of dementia. Dement Geriatr Cogn Disord 2006, 22(5-6):445-448.

93. Chung AK, Chua SE: Effects on prolongation of Bazett's corrected QT interval of seven second-generation antipsychotics in the treatment of schizophrenia: a meta-analysis. J Psychopharmacol 2010, 25(5):646-666

94. Canada Vigilance, Health Canada: Zeldox: Summary of Reported Adverse Reactions.: Canada Vigilance National Office, Government of Canada; Report request: March 26, 2010 (David Gardner). Report provided: March 29, 2010.

95. Alipour A, Cruz R, Lott RS: Torsade de pointes after ziprasidone overdose with coingestants. J Clin Psychopharmacol 2010, 30(1):76-77.

96. Haddad PM, Anderson IM: Antipsychotic-related QTc prolongation, torsade de pointes and sudden death. Drugs 2002, 62(11):1649-1671.

97. Tan HH, Hoppe J, Heard K: A systematic review of cardiovascular effects after atypical antipsychotic medication overdose. Am J Emerg Med 2009, 27(5):607-616.

98. Addington DE, Pantelis C, Dineen M, Benattia I, Romano SJ: Efficacy and tolerability of ziprasidone versus risperidone in patients with acute exacerbation of schizophrenia or schizoaffective disorder: an 8-week, double-blind, multicenter trial. J Clin Psychiatry 2004, 65(12):1624-1633.

99. Rummel-Kluge C, Komossa K, Schwarz S, Hunger H, Schmid F, Kissling W, Davis JM, Leucht S: Second-generation antipsychotic drugs and extrapyramidal side effects: a systematic review and meta-analysis of head-to-head comparisons. Schizophr Bull 2012, 38(1):167-177.

100. Miller DD, Caroff SN, Davis SM, Rosenheck RA, McEvoy JP, Saltz BL, Riggio S, Chakos MH, Swartz MS, Keefe RS, Stroup TS, Lieberman JA, Clinical Antipsychotic Trials of Intervention Effectiveness (CATIE) Investigators: Extrapyramidal side-effects of antipsychotics in a randomised trial. Br J Psychiatry 2008, 193(4):279-288.

101. Weiden PJ, Daniel DG, Simpson G, Romano SJ: Improvement in indices of health status in outpatients with schizophrenia switched to ziprasidone. J Clin Psychopharmacol 2003, 23(6):595-600.

102. Mendhekar DN: Ziprasidone-induced tardive dyskinesia. Can J Psychiatry 2005, 50(9):567-568.

103. Sinha P, Rao R, Sharan P: Ziprasidone-induced tardive dyskinesia in a patient without known risk factors. Natl Med J India 2007, 20(5):271-272.

104. Ananth J, Burgoyne KS, Niz D, Smith M: Tardive dyskinesia in 2 patients treated with ziprasidone. J Psychiatry Neurosci 2004, 29(6):467-469.

105. Borovicka MC, Bond LC, Gaughan KM: Ziprasidone- and lithium-induced neuroleptic malignant syndrome. Ann Pharmacother 2006, 40(1):139-142.

106. Leibold J, Patel V, Hasan RA: Neuroleptic malignant syndrome associated with ziprasidone in an adolescent. Clin Ther 2004, 26(7):1105-1108. 
107. Ozen ME, Yumru M, Savas HA, Cansel N, Herken H: Neuroleptic malignant syndrome induced by ziprasidone on the second day of treatment. World J Biol Psychiatry 2007, 8(1):42-44.

108. Murty RG, Mistry SG, Chacko RC: Neuroleptic malignant syndrome with ziprasidone. J Clin Psychopharmacol 2002, 22(6):624-626.

109. Pfizer: Geodon Prescribing Information. New York, NY: Roereg; 2009.

110. Mohan T, Bastiampillai T, Dhillon R: Ziprasidone-induced angioedema: a case report. J Clin Psychiatry 2009, 70(7):1054

111. Akkaya C, Sarandol A, Aydogan K, Kirli S: Urticaria and angio-oedema due to ziprasidone. J Psychopharmacol 2007, 21(5):550-552.

112. Jhirwal OP, Avasthi A: Ziprasidone-induced skin reaction: a case report from Indian subcontinent. Indian J Psychiatry 2003, 45(1):64-65.

113. Foley DL, Morley Kl: Systematic review of early cardiometabolic outcomes of the first treated episode of psychosis. Arch Gen Psychiatry 2011, 68(6):609-616.

114. Haffner SM: Relationship of metabolic risk factors and development of cardiovascular disease and diabetes. Obesity (Silver Spring) 2006, 14(Suppl 3):121S-127S

115. Baptista T: Body weight gain induced by antipsychotic drugs: mechanisms and management. Acta Psychiatr Scand 1999, 100(1):3-16.

116. Deng C, Weston-Green $\mathrm{K}$, Huang XF: The role of histaminergic $\mathrm{H} 1$ and $\mathrm{H} 3$ receptors in food intake: a mechanism for atypical antipsychotic-induced weight gain? Prog Neuropsychopharmacol Biol Psychiatry 2010, 34(1):1-4.

117. Hosojima H, Togo T, Odawara T, Hasegawa K, Miura S, Kato Y, Kanai A, Kase A, Uchikado H, Hirayasu Y: Early effects of olanzapine on serum levels of ghrelin, adiponectin and leptin in patients with schizophrenia. J Psychopharmacol 2006, 20(1):75-79.

118. Muller DJ, Zai CC, Sicard M, Remington E, Souza RP, Tiwari AK, Hwang R, Likhodi O, Shaikh S, Freeman N, Arenovich T, Heinz A, Meltzer HY, Lieberman JA, Kennedy JL: Systematic analysis of dopamine receptor genes (DRD1-DRD5) in antipsychotic-induced weight gain. Pharmacogenomics J 2012, 12(2):156-164.

119. Palik E, Birkas KD, Faludi G, Karadi I, Cseh K: Correlation of serum ghrelin levels with body mass index and carbohydrate metabolism in patients treated with atypical antipsychotics. Diabetes Res Clin Pract 2005, 68(Suppl 1):S60-S64.

120. Perez-Iglesias R, Mata I, Amado JA, Berja A, Garcia-Unzueta MT, Martinez Garcia O, Arranz MJ, Vazquez-Barquero JL, Crespo-Facorro B: Effect of FTO, $\mathrm{SH} 2 \mathrm{~B} 1, \mathrm{LEP}$, and LEPR polymorphisms on weight gain associated with antipsychotic treatment. J Clin Psychopharmacol 2010, 30(6):661-666.

121. Reynolds GP, Hill MJ, Kirk SL: The $5-\mathrm{HT} 2 \mathrm{C}$ receptor and antipsychoticinduced weight gain - mechanisms and genetics. $J$ Psychopharmacol 2006, 20(4 Suppl):15-18.

122. Sicard MN, Zai CC, Tiwari AK, Souza RP, Meltzer HY, Lieberman JA, Kennedy $J$, Muller DJ: Polymorphisms of the HTR2C gene and antipsychoticinduced weight gain: an update and meta-analysis. Pharmacogenomics 2010, 11(11):1561-1571.

123. Gentile S: Contributing factors to weight gain during long-term treatment with second-generation antipsychotics. A systematic appraisal and clinical implications. Obes Rev 2009, 10(5):527-542.

124. Hermes E, Nasrallah H, Davis V, Meyer J, McEvoy J, Goff D, Davis S, Stroup TS, Swartz M, Lieberman J, Rosenheck R: The association between weight change and symptom reduction in the CATIE schizophrenia trial. Schizophr Res 2011, 128(1-3):166-170.

125. Rummel-Kluge C, Komossa K, Schwarz S, Hunger H, Schmid F, Lobos CA, Kissling W, Davis JM, Leucht S: Head-to-head comparisons of metabolic side effects of second generation antipsychotics in the treatment of schizophrenia: a systematic review and meta-analysis. Schizophr Res 2010, 123(2-3):225-233.

126. Parsons B, Allison DB, Loebel A, Williams K, Giller E, Romano S, Siu C: Weight effects associated with antipsychotics: a comprehensive database analysis. Schizophr Res 2009, 110(1-3):103-110.

127. Lieberman JA, Stroup TS, McEvoy JP, Swartz MS, Rosenheck RA, Perkins DO, Keefe RS, Davis SM, Davis CE, Lebowitz BD, Severe J, Hsiao JK, Clinical Antipsychotic Trials of Intervention Effectiveness (CATIE) Investigators: Effectiveness of antipsychotic drugs in patients with chronic schizophrenia. N Engl J Med 2005, 353(12):1209-1223.

128. Weiden PJ, Newcomer JW, Loebel AD, Yang R, Lebovitz HE: Long-term changes in weight and plasma lipids during maintenance treatment with ziprasidone. Neuropsychopharmacology 2008, 33(5):985-994.

129. Nyhuis AW, Faries DE, Ascher-Svanum H, Stauffer VL, Kinon BJ: Predictors of switching antipsychotic medications in the treatment of schizophrenia. BMC Psychiatry 2010, 10:75
130. Rosenheck RA, Davis S, Covell N, Essock S, Swartz M, Stroup S, McEvoy J, Lieberman J: Does switching to a new antipsychotic improve outcomes? Data from the CATIE Trial. Schizophr Res 2009, 107(1):22-29.

131. Alptekin K, Hafez J, Brook S, Akkaya C, Tzebelikos E, Ucok A, El Tallawy H, Danaci $A E$, Lowe W, Karayal ON: Efficacy and tolerability of switching to ziprasidone from olanzapine, risperidone or haloperidol: an international, multicenter study. Int Clin Psychopharmacol 2009, 24(5):229-238.

132. Weinmann S, Read J, Aderhold V: Influence of antipsychotics on mortality in schizophrenia: systematic review. Schizophr Res 2009, 113(1):1-11.

133. Maayan L, Vakhrusheva J, Correll CU: Effectiveness of medications used to attenuate antipsychotic-related weight gain and metabolic abnormalities: a systematic review and meta-analysis. Neuropsychopharmacology 2010, 35(7):1520-1530.

134. Praharaj SK, Jana AK, Goyal N, Sinha VK: Metformin for olanzapine-induced weight gain: a systematic review and meta-analysis. $\mathrm{Br} J$ Clin Pharmacol 2011, 71(3):377-382.

135. Allison DB, Mentore JL, Heo M, Chandler LP, Cappelleri JC, Infante MC, Weiden PJ: Antipsychotic-induced weight gain: a comprehensive research synthesis. Am J Psychiatry 1999, 156(11):1686-1696.

136. Alvarez-Jimenez M, Martinez-Garcia O, Perez-Iglesias R, Ramirez ML, Vazquez-Barquero JL, Crespo-Facorro B: Prevention of antipsychoticinduced weight gain with early behavioural intervention in first-episode psychosis: 2-year results of a randomized controlled trial. Schizophr Res 2010, 116(1):16-19.

137. Simon V, van Winkel R, De Hert M: Are weight gain and metabolic side effects of atypical antipsychotics dose dependent? A literature review. J Clin Psychiatry 2009, 70(7):1041-1050.

138. Taylor DM, McAskill R: Atypical antipsychotics and weight gain-a systematic review. Acta Psychiatr Scand 2000, 101(6):416-432.

139. Ferket BS, Colkesen EB, Visser JJ, Spronk S, Kraaijenhagen RA, Steyerberg EW, Hunink MG: Systematic review of guidelines on cardiovascular risk assessment: Which recommendations should clinicians follow for a cardiovascular health check? Arch Intern Med 2010, 170(1):27-40.

140. Vitiello B, Correll C, van Zwieten-Boot B, Zuddas A, Parellada M, Arango C: Antipsychotics in children and adolescents: increasing use, evidence for efficacy and safety concerns. Eur Neuropsychopharmacol 2009, 19(9):629-635.

141. Aparasu RR, Bhatara V: Patterns and determinants of antipsychotic prescribing in children and adolescents, 2003-2004. Curr Med Res Opin 2007, 23(1):49-56.

142. Cooper WO, Hickson GB, Fuchs C, Arbogast PG, Ray WA: New users of antipsychotic medications among children enrolled in TennCare. Arch Pediatr Adolesc Med 2004, 158:753-759.

143. Cooper WO, Arbogast PG, Ding H, Hickson GB, Fuchs DC, Ray WA: Trends in prescribing of antipsychotic medications for US children. Ambul Pediatr 2006, 6(2):79-83.

144. Fox MH, Foster $\mathrm{CH}$, Zito JM: Building pharmacoepidemiological capacity to monitor psychotropic drug use among children enrolled in Medicaid. Am J Med Qual 2000, 15(4):126-136.

145. Goodwin R, Gould MS, Blanco C, Olfson M: Prescription of psychotropic medications to youths in office-based practice. Psychiatr Serv 2001 52(8):1081-1087.

146. Greenhill LL, Vitiello B, Riddle MA, Fisher P, Shockey E, March JS, Levine J, Fried J, Abikoff H, Zito JM, McCracken JT, Findling RL, Robinson J, Cooper TB, Davies M, Varipatis E, Labellarte MJ, Scahill L, Walkup JT, Capasso L, Rosengarten J: Review of safety assessment methods used in pediatric psychopharmacology. J Am Acad Child Adolesc Psychiatry 2003, 42(6):627-633.

147. Khaled LA, Ahmed F, Brogan T, Fearnley J, Graham J, MacLeod S, McCormack J: Prescription medicine use by one million Canadian children. Paedetrics \& Child Health 2003, 8(Suppl A):6A-56A.

148. Olfson M, Blanco C, Liu L, Moreno C, Laje G: National trends in the outpatient treatment of children and adolescents with antipsychotic drugs. Arch Gen Psychiatry 2006, 63(6):679-685.

149. Pappadopulos E, Jensen PS, Schur SB, Pappadopulos E, Jensen PS, Schur SB, Maclntyre JC II, Ketner S, Van Orden K, Sverd J, Sardana S, Woodlock D, Schweitzer R, Rube D: "Real world" atypical antipsychotic prescribing practices in public child and adolescent inpatient settings. Schizophr Bull 2002, 28(1):111-121.

150. Patel NC, Crismon ML, Hoagwood K, Johnsrud MT, Rascati KL, Wilson JP, Jensen PS: Trends in the use of typical and atypical antipsychotics in children and adolescents. J Am Acad Child Adolesc Psychiatry 2005, 44(6):548-556 
151. Patel NC, Crismon ML, Shafer A: Diagnoses and antipsychotic treatment among youths in a public mental health system. Ann Pharmacother 2006, 40(2):205-211.

152. Patel NC, DelBello MP, Keck PE Jr, Strakowski SM: Ethnic differences in maintenance antipsychotic prescription among adolescents with bipolar disorder. J Child Adolesc Psychopharmacol 2005, 15(6):938-946.

153. Patel NC, Sanchez RJ, Johnsrud MT, Crismon ML: Trends in antipsychotic use in a Texas medicaid population of children and adolescents: 1996 to 2000. J Child Adolesc Psychopharmacol 2002, 12(3):221-229.

154. Rani F, Murray ML, Byrne PJ, Wong IC: Epidemiologic features of antipsychotic prescribing to children and adolescents in primary care in the United Kingdom. Pediatrics 2008, 121(5):1002-1009.

155. Schirm E, Tobi H, Zito JM, den De Jong-van Berg LT: Psychotropic medication in children: a study from the Netherlands. Pediatrics 2001, 108(2):E25.

156. Vitiello B, Riddle MA, Greenhill LL, March JS, Levine J, Schachar RJ, Abikoff H, Zito JM, McCracken JT, Walkup JT, Findling RL, Robinson J, Cooper TB, Davies M, Varipatis E, Labellarte MJ, Scahill L, Capasso L: How can we improve the assessment of safety in child and adolescent psychopharmacology? J Am Acad Child Adolesc Psychiatry 2003, 42(6):634-641.

157. Zito JM, Safer DJ, DosReis S, Gardner JF, Boles M, Lynch F: Trends in the prescribing of psychotropic medications to preschoolers. JAMA 2000, 283(8):1025-1030.

158. Zito JM, Safer DJ, DosReis S, Riddle MA: Racial disparity in psychotropic medications prescribed for youths with Medicaid insurance in Maryland. J Am Acad Child Adolesc Psychiatry 1998, 37(2):179-184.

159. Zito JM, Safer DJ, Riddle MA, Johnson RE, Speedie SM, Fox M: Prevalence variations in psychotropic treatment of children. J Child Adolesc Psychopharmacol 1998, 8(2):99-105

160. Olfson M, Gerhard T, Huang C, Lieberman JA, Bobo W, Crystal S: Comparative effectiveness of second-generation antipsychotic medications in earlyonset schizophrenia. Schizophr Bull 2011, 38(4):845-853.

161. De Hert M, Dobbelaere M, Sheridan EM, Cohen D, Correll CU: Metabolic and endocrine adverse effects of second-generation antipsychotics in children and adolescents: A systematic review of randomized, placebo controlled trials and guidelines for clinical practice. Eur Psychiatry 2011, 26(3):144-158.

162. Penfold RB, Kelleher KJ, Wang W, Strange B, Pajer K: Pediatric uptake of a newly available antipsychotic medication. Pediatrics 2010, 125(3):475-482.

163. Elbe D, Carandang CG: Focus on ziprasidone: a review of its use in child and adolescent psychiatry. J Can Acad Child Adolesc Psychiatry 2008, 17(4):220-229.

164. Myers SM: The status of pharmacotherapy for autism spectrum disorders. Expert Opin Pharmacother 2007, 8(11):1579-1603.

165. Myers SM, Johnson CP, American Academy of Pediatrics Council on Children With Disabilities: Management of children with autism spectrum disorders. Pediatrics 2007, 120(5):1162-1182.

166. Correll CU: Metabolic side effects of second-generation antipsychotics in children and adolescents: a different story? J Clin Psychiatry 2005, 66(10):1331-1332.

167. Sallee FR, Kurlan R, Goetz CG, Singer H, Scahill L, Law G, Dittman VM, Chappell PB: Ziprasidone treatment of children and adolescents with Tourette's syndrome: a pilot study. J Am Acad Child Adolesc Psychiatry 2000, 39(3):292-299.

168. DelBello MP, Versavel M, Ice K, Keller D, Miceli J: Tolerability of oral ziprasidone in children and adolescents with bipolar mania, schizophrenia, or schizoaffective disorder. J Child Adolesc Psychopharmacol 2008, 18(5):491-499.

169. Jerrell JM, Hwang TL, Livingston TS: Neurological adverse events associated with antipsychotic treatment in children and adolescents. J Child Neurol 2008, 23(12):1392-1399.

170. Neuhut R, Lindenmayer JP, Silva R: Neuroleptic malignant syndrome in children and adolescents on atypical antipsychotic medication: a review. J Child Adolesc Psychopharmacol 2009, 19(4):415-422

171. Ramos AE, Shytle RD, Silver AA, Sanberg PR: Ziprasidone-induced oculogyric crisis. J Am Acad Child Adolesc Psychiatry 2003, 42(9):1013-1014.

172. Gupta S, Nolan TN, Frank BL: Case report of oculogyric crisis with ziprasidone in a minor. Prim Care Companion J Clin Psychiatry 2008, 10(3):254-255.

173. Blair J, Scahill L, State M, Martin A: Electrocardiographic changes in children and adolescents treated with ziprasidone: a prospective study. J Am Acad Child Adolesc Psychiatry 2005, 44(1):73-79.
174. Snarr BS, Phan SV, Garner A, VandenBerg AM, Barth KS: Symptomatic bradycardia with oral aripiprazole and oral ziprasidone. Ann Pharmacother 2010, 44(4):760-763.

175. Jordan MP: Ziprasidone-associated galactorrhea in a female teenager. J Am Acad Child Adolesc Psychiatry 2003, 42(1):4-5.

176. Saldana SN, Delgado SV: Ziprasidone-associated galactorrhea in an adolescent female. J Child Adolesc Psychopharmacol 2007, 17(2):259-260.

177. Gentile S: Second-generation antipsychotics in dementia: beyond safety concerns. A clinical, systematic review of efficacy data from randomised controlled trials. Psychopharmacology (Berl) 2010, 212(2):119-129.

178. Ballard CG, Waite J, Birks J: Atypical antipsychotics for aggression and psychosis in Alzheimer's disease. Cochrane Database of Systematic Reviews 2006, doi:10.1002/14651858.CD003476.pub2. Issue 1. Art. No.: CD003476.

179. Byerly MJ, Thompson A, Carmody T, Bugno R, Erwin T, Kashner M, Rush AJ: Validity of electronically monitored medication adherence and conventional adherence measures in schizophrenia. Psychiatr Serv 2007, 58(6):844-847.

180. Velligan DI, Wang M, Diamond P, Glahn DC, Castillo D, Bendle S, Lam YW, Ereshefsky L, Miller AL: Relationships among subjective and objective measures of adherence to oral antipsychotic medications. Psychiatr Serv 2007, 58(9):1187-1192.

181. Johnsen E, Kroken RA, Wentzel-Larsen T, Jorgensen HA: Effectiveness of second-generation antipsychotics: a naturalistic, randomized comparison of olanzapine, quetiapine, risperidone, and ziprasidone. BMC Psychiatry 2010, 10:26

182. Moisan J, Gregoire JP: Patterns of discontinuation of atypical antipsychotics in the province of Quebec: A retrospective prescription claims database analysis. Clin Ther 2010, 32(Suppl 1):S21-S31.

183. Velligan DI, Weiden PJ, Sajatovic M, Scott J, Carpenter D, Ross R, Docherty $J P$, Expert Consensus Panel on Adherence Problems in Serious and Persistent Mental IIIness: The expert consensus guideline series: adherence problems in patients with serious and persistent mental illness. J Clin Psychiatry 2009, 70(Suppl 4):1-46. quiz 47-8.

184. Kemmler G, Hummer M, Widschwendter C, Fleischhacker WW: Dropout rates in placebo-controlled and active-control clinical trials of antipsychotic drugs: a meta-analysis. Arch Gen Psychiatry 2005, 62(12):1305-1312.

185. Citrome L, Yang R, Glue P, Karayal ON: Effect of ziprasidone dose on allcause discontinuation rates in acute schizophrenia and schizoaffective disorder: a post-hoc analysis of 4 fixed-dose randomized clinical trials. Schizophr Res 2009, 111(1-3):39-45.

186. Joyce AT, Harrison DJ, Loebel AD, Carter CT, Ollendorf DA: Effect of initial ziprasidone dose on length of therapy in schizophrenia. Schizophr Res 2006, 83(2-3):285-292.

187. Pae CU, Kim JJ, Lee CU, Lee SJ, Lee C, Patkar AA, Masand PS, Paik IH: Rapid versus conventional initiation of quetiapine in the treatment of schizophrenia: a randomized, parallel-group trial. J Clin Psychiatry 2007 68(3):399-405

188. Boidi G, Ferro M: Rapid dose initiation of quetiapine for the treatment of acute schizophrenia and schizoaffective disorder: a randomised, multicentre, parallel-group, open study. Hum Psychopharmacol 2007, 22(5):299-306

189. Citrome L, Reist C, Palmer L, Montejano LB, Lenhart G, Cuffel B, Harnett J, Sanders KN: Impact of real-world ziprasidone dosing on treatment discontinuation rates in patients with schizophrenia or bipolar disorder. Schizophr Res 2009, 115(2-3):115-120.

190. Fagiolini A, Canas F, Gallhofer B, Larmo I, Levy P, Montes JM, Papageorgiou G, Zink M, Rossi A: Strategies for successful clinical management of schizophrenia with ziprasidone. Expert Opin Pharmacother 2010, 11(13):2199-2220.

191. Maclntosh D, Procyshyn RM: Switch Rx: switching antipsychotic medications. http://switchrx.ca.

192. Rossi A, Canas F, Fagiolini A, Larmo I, Levy P, Montes JM, Papageorgiou G, Sturlason R, Zink M, Correll CU: Switching among antipsychotics in everyday clinical practice: focus on ziprasidone. Postgrad Med 2011, 123(1):135-159.

doi:10.1186/1744-859X-12-1

Cite this article as: Gardner et al:: Evidence review and clinical guidance for the use of ziprasidone in Canada. Annals of General Psychiatry 2013 $12: 1$. 